\title{
Analysis of notch effect in the apparent fracture toughness and the fracture micromechanisms of ferritic-pearlitic steels operating within their lower shelf
}

\author{
S. Cicero, V. Madrazo, T. García \\ Universidad de Cantabria, Materials Science and Engineering Department, Av/Los Castros s/n, 39005 \\ Santander, Cantabria, Spain. ciceros@unican.es
}

\begin{abstract}
The fracture resistance of materials is generally higher in notched conditions that in cracked conditions. In other words, when the notch radius increases there is also an increase in the apparent fracture toughness, which is that exhibited in notched conditions. This paper presents an analysis of the notch effect on two ferritic-pearlitic steels operating within their corresponding lower shelf, and develops an experimental programme, composed of $28 \mathrm{CT}$ characterisation specimens and $72 \mathrm{CT}$ validation specimens, together with finite elements analysis with the aim of validating the apparent fracture toughness predictions provided by the Theory of Critical Distances. The results have shown how this theory provides reasonable predictions of the apparent fracture toughness of the material
\end{abstract}

The research is completed with the analysis of the evolution of fracture micromechanisms when the notch radius increases, revealing a direct relation between this evolution and the apparent fracture toughness observations.

Keywords: notch, apparent fracture toughness, ferritic-pearlitic steel, fracture, lower shelf 


\section{Introduction}

Notched components present a fracture resistance, usually named apparent fracture toughness, which is greater than the fracture toughness observed in cracked components [1-6]. Therefore, if notches are considered as cracks when performing fracture assessments, the corresponding results may be overconservative, so that assessment methodologies considering the actual behaviour of notches are necessary in order to obtain accurate results.

The analysis of the fracture behaviour of notches can be performed using two different criteria: the global criterion, which is analogous to the fracture analysis in cracked components, in which a parameter named notch stress intensity factor is compared to the corresponding critical material parameter; and local criteria, which are based on the stress-strain field at the notch tip. Among the latter, the Point Method (PM) and the Line Method (LM) stand out, both of these being methodologies of the Theory of Critical Distances (TCD). The TCD and its various approaches can be applied to the analysis of the load-bearing capacity of components containing any kind of stress risers, from plain specimens (those without any stress concentrations) to cracked components. This application is particularly simple in the case of the PM and the LM, two methodologies that can easily generate predictions of the apparent fracture toughness exhibited by notched components. Further details on the TCD and its different proposals for notch effect predictions are described in Section 2.

The main objectives of this paper are to analyse the notch effect in the apparent fracture toughness of steels S275JR [7] and S355J2 [7] when they operate within their lower shelf, to provide validation on the application of the TCD to the analysis of the notch effect in S275JR and S355J2, and to relate, if possible, the evolution of the resistant behaviour of the two steels with the fracture mechanisms.

All the research is focused on the lower shelf of the two materials analysed. It is known that the fracture resistance of ferritic-pearlitic steels presents a clear dependence on the working temperature, with brittle 
behaviour (in cracked conditions) at low temperatures (usually referred to as the lower shelf), ductile behaviour at high temperatures (upper shelf) and transition behaviour between the lower shelf and the upper shelf (ductile-to-brittle transition zone) [8-10]. Figure 1 represents a description of this type of behaviour. Thus, this paper covers those situations where ferritic-pearlitic steels present brittle behaviour in cracked conditions.

With all this, Section 2 gathers some theoretical background on the TCD, and Section 3 presents the experimental programme performed on S275JR and S355J2 fracture specimens.. After that, the finite elements modelling developed for the calibration of the material parameters is described in Section 4, the application of the TCD to the analysis of the notch effect in the two steels is gathered in Section 5, Section 6 presents the analysis of fracture micromechanisms and Section 7 the conclusions.

\section{Analysis of notches using the Theory of Critical Distances}

The Theory of Critical Distances (TCD) is actually a group of methodologies, all of which use a characteristic material length parameter (the critical distance, $L$ ) when performing fracture and fatigue assessments $[11,12]$. The origins of the TCD date back to the middle of the twentieth century, with the works of Neuber [13] and Peterson [14], but it has been in the last few years, driven by the proliferation of finite elements stress analysis, that this theory has been systematically analysed and applied to different types of materials (metals, ceramics, polymers and composites), failure or damage processes (basically fracture and fatigue) and conditions (e.g., linear-elastic vs. elastoplastic) [15-22].

The critical distance is usually referred to as $L$ and its expression is, in fracture analysis (in fatigue analysis, $L$ has an analogous expression that may be consulted in the bibliography [11]):

$$
L=\frac{1}{\pi}\left(\frac{K_{c}}{\sigma_{0}}\right)^{2}
$$


where $K_{c}$ is thel fracture toughness of the material and $\sigma_{0}$ is a characteristic material strength parameter named the inherent strength, which is usually larger than the ultimate tensile strength $\left(\sigma_{u}\right)$ and requires calibration. Only in those situations where there is a linear-elastic behaviour at both the micro and the macroscale (e.g., fracture of ceramics) does $\sigma_{0}$ coincide with $\sigma_{u}$.

Among the different methodologies included in the TCD [11], two of them are particularly simple to apply: the so-called PM and LM, which are based on the stress field at the defect tip.

The Point Method (PM) states that fracture occurs when the stress reaches the inherent strength $\left(\sigma_{0}\right)$ at a certain distance from the defect tip, $r_{c}$. From the stress field in a crack tip at failure $[9,11]$ and the definition of $L$ (equation (1)), it is straightforward to demonstrate that $r_{c}$ is $L / 2$ :

$$
\sigma\left(r_{c}\right)=\frac{K_{c}}{\sqrt{2 \pi r_{c}}}=\sigma_{0} \Rightarrow r_{c}=\frac{1}{2 \pi}\left(\frac{K_{c}}{\sigma_{0}}\right)^{2}=\frac{L}{2}
$$

The PM failure criterion is, therefore:

$$
\sigma\left(\frac{L}{2}\right)=\sigma_{0}
$$

On the other hand, the Line Method (LM) assumes that fracture occurs when the average stress along a certain distance, $d$ (starting from the defect tip), reaches the inherent strength, $\sigma_{0}$. From the stress field in a crack tip at failure and the definition of $L$, it is simple to demonstrate that $d$ is equal to $2 L$ :

$$
\frac{1}{d} \int_{0}^{d} \sigma(r) d r=\frac{1}{d} \int_{0}^{d} \frac{K_{c}}{\sqrt{2 \pi r}} d r=\frac{2}{\sqrt{2 \pi}} \frac{K_{c}}{d^{1 / 2}}=\sigma_{0} \Rightarrow d=\frac{4}{2 \pi}\left(\frac{K_{c}}{\sigma_{0}}\right)^{2}=2 L
$$

Therefore, the LM failure criterion is: 


$$
\frac{1}{2 L} \int_{0}^{2 L} \sigma(r) d r=\sigma_{0}
$$

As can be seen, a key aspect of the TCD, and thus the PM and the LM, is that it allows the fracture assessment of components with any kind of stress riser to be performed, provided the material parameters ( $L$ and $\sigma_{0}$ ) and the corresponding stress field are known. As an example, when using the PM it would be sufficient to perform two fracture tests on two specimens with different types of defects (e.g., sharp notch and blunt notch). The specimens can then be modelled with finite elements, determining the stress state on the notch tip at fracture load, and representing the corresponding stress-distance curves. These curves cross each other at a point with coordinates $\left(L / 2, \sigma_{0}\right)$, as shown in Figure 2. Now, if it is intended to predict the fracture load of any other component made of the same material and containing any defect, it would be necessary to perform the finite elements modelling of both the component and the defect, the fracture load being that one for which equation (3) is fulfilled. This methodology has previously been applied by Cicero et al. [23].

The TDC also allows components containing U-shaped notches to be analysed, given that both the PM and the LM provide expressions for the apparent fracture toughness $\left(K^{N}\right)$ exhibited by this type of notched components. This parameter reduces the fracture analysis in a component having a U-shaped notch to an equivalent situation in a cracked component, with the only particularity of considering $K^{N}{ }_{c}$ instead of $K_{c}$. Thus, fracture occurs when:

$$
K_{I}=K_{c}^{N}
$$

$K_{I}$ is the stress intensity factor for a crack with the same extension of the notch, and $K^{N}{ }_{c}$ may be obtained using the following expressions ( $\rho$ being the notch radius): 


$$
K_{c}^{N}=K_{c} \frac{\left(1+\frac{\rho}{L}\right)^{3 / 2}}{\left(1+\frac{2 \rho}{L}\right)}
$$

when using the PM, and

$$
K_{c}^{N}=K_{c} \sqrt{1+\frac{\rho}{4 L}}
$$

when using the LM.

The justification of these expressions is based on the Creager and Paris notch tip stress distribution [5], and may be found in the literature [11]. Here, it should be noted is important to notice that given that the Creager and Paris equation is only valid for deep thin notches (notch length $>\rho$ ), the validity of equations (7) and (8) is also limited by such notch conditions.

Once the bases of the PM and the LM have been explained, and the predictions of $K^{N}{ }_{c}$ for U-shaped notches have been defined, an experimental programme coupled with finite elements modelling has been performed in order to compare the apparent fracture toughness experimental results with the PM and LM predictions in ferritic-pearlitic steels S275JR and S275J2 operating at lower shelf temperatures.

\section{Materials and experimental programme}

This section presents the basic characterisation of the two materials being analysed, including chemical, microstructural and tensile analyses. Both materials were provided as $1000 \mathrm{~mm}$ x $2500 \mathrm{~mm}$ rolled plates, the thickness being $25 \mathrm{~mm}$ in the two cases. Table 1 gathers the chemical analysis, obtained by using chemical emission spectroscopy. The results were consistent with the specifications of both materials. 
Figures 3 and 4 show the ferritic-pearlitic microstructures of the two steels. It can be observed that the pearlitic grains are distributed more homogeneously in steel S275JR than in steel S355J2, which clearly presents alternated bands of perarlitic and ferritic nature. Moreover, the average grain size is rather different in the two steels. The corresponding grain size $(d)$ was determined following ASTM E112 [24], providing values of $19.4 \mu \mathrm{m}$ and $8.3 \mu \mathrm{m}$ for steels S275JR and S355J2, respectively.

14 Compact Tension (CT) cracked specimens, LT oriented [25], were tested for each material in order to determine the corresponding reference temperature [26], $T_{0}$. Figure 5 shows the geometry of the specimens. The reference temperature is that which corresponds to a median value of $K_{J c}$ [26] of 100 $\mathrm{MPam}^{1 / 2}$ obtained in $25 \mathrm{~mm}$ thick specimens, and defines, through the Master Curve [26], the ductile-tobrittle transition zone. In the case of steel S275JR, six tests were performed at $-10^{\circ} \mathrm{C}$, four at $-30^{\circ} \mathrm{C}$ and four at $-50^{\circ} \mathrm{C}$, providing a $T_{0}$ of $-26^{\circ} \mathrm{C}$; in the case of steel $\mathrm{S} 355 \mathrm{~J} 2$, six tests were performed at $-100^{\circ} \mathrm{C}$, four at $-120^{\circ} \mathrm{C}$ and four at $-150^{\circ} \mathrm{C}$, providing a $T_{0}$ value of $-133^{\circ} \mathrm{C}$. The precracking process was performed at room temperature and following the conditions established in ASTM E1921 [26]. Thus, a $\mathrm{K}_{\max } / \mathrm{E}$ ratio of $0.00013 \mathrm{~m}^{1 / 2}$ was applied for the crack initiation, and a $\left(\mathrm{K}_{\max } / \mathrm{E}\right) \cdot\left(\sigma_{y(R T)} / \sigma_{y(T T)}\right)$ value of $0.000096 \mathrm{~m}^{1 / 2}$ was applied for the finish sharpening $\left(\sigma_{y(R T)}\right.$ being the yield stress at room temperature and $\sigma_{y(T T)}$ being the yield stress at the corresponding testing temperature). The applied stress ratio (R) was 0.1 in all cases. The fracture toughness result for each individual test is shown in Table 2.

Once the $T_{0}$ was determined for each material, the test temperatures at the lower shelf were estimated. The above mentioned Master Curve, which models the ductile-to-brittle transition zone, has a temperature validity range of $T_{0} \pm 50^{\circ} \mathrm{C}$. Therefore, lower shelf temperatures are necessarily lower than $T_{0^{-}}-50^{\circ} \mathrm{C}$. With this criterion it was decided to test steel S275JR at $-90^{\circ} \mathrm{C}\left(64{ }^{\circ} \mathrm{C}\right.$ below $\left.T_{0}\right)$ and $-120^{\circ} \mathrm{C}\left(94{ }^{\circ} \mathrm{C}\right.$ below $\left.T_{0}\right)$, and steel $\mathrm{S} 355 \mathrm{~J} 2$ at $-196^{\circ} \mathrm{C}\left(63^{\circ} \mathrm{C}\right.$ below the corresponding $\left.T_{0}\right)$. In the latter case, there was only one testing temperature, given that it was not possible to conduct tests at lower temperatures (liquid nitrogen combined with an environmental chamber were used as the cooling system). In any case, the three temperatures are well below the corresponding reference temperature, and therefore it has been assumed to represent temperatures belonging to the lower shelf of the two materials being analysed. 
Tensile tests of each material were performed (following ASTM E8/E8M-11 [27]) at every temperature of interest in order to determine the tensile properties of the material being analysed. The tests were performed in round tension specimens with $50 \mathrm{~mm}$ gauge length, $10 \mathrm{~mm}$ diameter and $8 \mathrm{~mm}$ fillet radius. The applied loading rate was $0.02 \mathrm{~mm} / \mathrm{sec}$. The main material parameters are gathered in Table $3 . E$ is the Young's modulus, $\sigma_{y}$ is the yield stress and $\sigma_{u}$ the ultimate tensile strength.

Finally, fracture tests on CT specimens (also LT oriented and with the geometry shown in Figure 5) were performed at $-90^{\circ} \mathrm{C}$ and $-120^{\circ} \mathrm{C}$ for $\mathrm{S} 275 \mathrm{JR}$, and at $-196^{\circ} \mathrm{C}$ for $\mathrm{S} 355 \mathrm{~J} 2$, in both cases following E1820-11 [8] (see Figure 6). The width $(W)$ and the thickness $(B)$ of the specimens [8] were $50 \mathrm{~mm}$ and $25 \mathrm{~mm}$, respectively, and the loading rate was $0.05 \mathrm{~mm} / \mathrm{sec}$ [8]. A total amount of 72 tests were performed, 24 at $90^{\circ} \mathrm{C}$ and 24 at $-120^{\circ} \mathrm{C}$ in steel S275JR and 24 at $-196^{\circ} \mathrm{C}$ in steel S355J2. Each set of 24 specimens corresponds to six different notch radii varying from $0 \mathrm{~mm}$ (crack-type defects) to $2.0 \mathrm{~mm}$. The notches were performed by electrical discharge machining (EDM), except for those whose notch radius was considered to be zero, which were generated by fatigue precracking under the same conditions established above for the specimens used to determine $T_{0}$. These conditions satisfy the requirements established in ASTM E1820-11 [8]. Tables 4 and 5 gather the different tests with the corresponding notch radii for steels S275JR and S355J2, respectively.

Figures 7 to 9 show, as an example, the load-displacement curves obtained in the tests corresponding to some of the notch radii in S275JR and S355J2 specimens, respectively. In particular for S275JR at both temperatures the selected notch radii are $0,0.5$ and $2.0 \mathrm{~mm}$ and for $\mathrm{S} 355 \mathrm{~J} 2$ are $0.15,0.5$ and $2.0 \mathrm{~mm}$. It can be seen that the slope of the curves is basically the same for all the specimens corresponding to the same material. Moreover, there is a significant loss of linearity in the load-displacement curves obtained in specimens with higher radii.

Tables 4 and 5 also gather the results obtained in terms of the apparent fracture toughness $\left(K^{N}{ }_{c}\right)$, obtained by the application of the cracked specimen formulation [8] to notched specimens: 


$$
K_{c}^{N}=\sqrt{J_{c}^{N} \frac{E}{1-v^{2}}}
$$

$$
J_{c}^{N}=J_{e}^{N}+J_{p}^{N}=\frac{\left(1-v^{2}\right)\left(K_{e}^{N}\right)^{2}}{E}+\frac{\eta A_{p}}{B b_{0}}
$$

where $J^{N}{ }_{c}$ is the apparent J-integral at onset of cleavage fracture, $E$ is the Young's modulus and $v$ is the Poisson's ratio [8]. $J^{N}{ }_{e}$ and $J^{N}{ }_{p}$ are, respectively, the elastic and plastic components of $J_{c}^{N}, K^{N}{ }_{e}$ is the apparent elastic stress intensity factor at onset of cleavage (see equation (11)), $\eta$ is a dimensionless constant, $A_{p}$ is the plastic area under the load-displacement curve, and $b_{0}$ is the initial remaining ligament [8].

$K_{e}^{N}=\left(\frac{P_{\max }}{B W^{0.5}}\right) \frac{2+\frac{a}{W}}{\left(1-\frac{a}{W}\right)^{3 / 2}}\left(0.886+4.64\left(\frac{a}{W}\right)-13.32\left(\frac{a}{W}\right)^{2}+14.72\left(\frac{a}{W}\right)^{3}-5.60\left(\frac{a}{W}\right)^{4}\right)$

where $P_{\max }$ is the corresponding maximum load, $B$ is the specimen thickness, $W$ is the specimen width, and $a$ is the defect length [8]

$K^{N}{ }_{c}$ results are also shown graphically in Figures 10 to 12 . The main observations about the obtained results are the following:

- The fracture toughness, $K_{c}$, obtained as the mean value of the cracked specimens, is $48.8 \mathrm{MPam}^{1 / 2}$ for S275JR at $-120^{\circ} \mathrm{C}, 62.7 \mathrm{MPam}^{1 / 2}$ for $\mathrm{S} 275 \mathrm{JR}$ at $-90^{\circ} \mathrm{C}$, and $31.3 \mathrm{MPam}^{1 / 2}$ for $\mathrm{S} 355 \mathrm{~J} 2$ at $196^{\circ} \mathrm{C}$. Thus, steel S355J2 presents a more brittle behaviour than steel S275JR at the temperatures analysed. 
- A clear notch effect can be appreciated in both materials, with a significant increase in the apparent fracture toughness with the notch radius. This notch effect is particularly high in steel S275JR, where the average apparent fracture toughness in specimens with a notch radius of 2.0 $\mathrm{mm}$ is 7 times higher than the average fracture toughness measured in cracked specimens at $-120^{\circ} \mathrm{C}$, and 9.6 times higher at $-90^{\circ} \mathrm{C}$. In the case of steel $\mathrm{S} 355 \mathrm{~J} 2$, this factor is equal to 4 at $196^{\circ} \mathrm{C}$.

- It is important to notice the high values of apparent fracture toughness that have been measured in notched conditions. Thus, steel S275JR at $-120^{\circ} \mathrm{C}$ presents an average value of $345.0 \mathrm{MPam}^{1 / 2}$ when the notch radius is $2.0 \mathrm{~mm}$ (the maximum value being $578.2 \mathrm{MPam}^{1 / 2}$ ). At $-90^{\circ} \mathrm{C}$ the average value is $604.1 \mathrm{MPam}^{1 / 2}$ in specimens with a notch radius of $2.0 \mathrm{~mm}$, the maximum being 830.8 $\mathrm{MPam}^{1 / 2}$. In the case of steel S355J2, the observed values are also high but much more moderate, with an average value of $125.8 \mathrm{MPam}^{1 / 2}$ (2.0 mm notch radius) and a maximum value of $141.1 \mathrm{MPam}^{1 / 2}$.

- In all cases, specimens with a $2.0 \mathrm{~mm}$ notch radius have presented higher scatter than those with smaller radii.

- There are no indications of the existence of a critical radius below which the notch effect is negligible. The critical radius has been reported in other research on the notch effect in different types of materials $[1-6,11,12]$. In others words, the smallest finite notch radius introduced in the material $(0.15 \mathrm{~mm})$ generates a noticeable notch effect, with a higher apparent fracture toughness than that obtained in cracked conditions.

\section{Finite elements modelling and calibration of the critical distance}

Finite elements (FE) modelling was performed using ANSYS 12.1 in order to determine the stress field at the notch tip in the different specimens. Each geometry, corresponding to each type of notch radius (see 
Figure 13), was subjected to the average failure load of the different specimens with the same notch radius, material and temperature, and the stress-distance curve in the middle line of the fracture section was obtained (the origin being located in the defect tip). For this purpose, three different material behaviours, corresponding to S275JR at $-120^{\circ} \mathrm{C}, \mathrm{S} 275 \mathrm{JR}$ at $-90^{\circ} \mathrm{C}$ and $\mathrm{S} 355 \mathrm{~J} 2$ at $-196^{\circ} \mathrm{C}$ (see Table 3), were considered in the analysis. Following the literature (e.g., $[10,12])$, the simulation was conducted in purely linear-elastic conditions, despite the non-linear (plastic) phenomena occurring on the defect tip in some of the specimens. Finally, the mesh was performed using SOLID186 elements (3D, 20-node solid elements with quadratic displacement behaviour), the mesh being much more refined at the defect tip, because of the higher gradients appearing in this zone, with element sizes of the same order as the finally obtained critical distances.

On the different stress fields that were obtained, the PM was applied in order to calibrate the material parameters of the TDC. For the sake of simplicity, curves corresponding to notch radii of $0 \mathrm{~mm}$ (cracked conditions) and $0.15 \mathrm{~mm}$ have been considered in the calibration process. Some recommendations are presented in the literature $[21,22]$ for those situations in which a higher number of stress profiles are available in the calibration process. The main recommendations are the following: 1) to limit the stressstrain curves used in the calibration to those corresponding to a Neuber number ( $\rho / L$ [11]) below 20, and; 2) do not combine stress-strain curves corresponding to different stress field conditions (i.e., plane strain vs. plane stress). Figures 14 to 16 show the corresponding stress-distance curves where, for each combination of material and temperature, the curves cross at a single point. Table 6 shows the corresponding results.

Here, two main observations can be made:

- $\quad L$ values seem to be very low, but the same order of magnitude has been reported [11] in other metallic materials having high tensile properties and low fracture toughness. Analogous observations can be made concerning the high values of the inherent strength. 
The values obtained for the critical distances have the same order of magnitude as the corresponding grain size $(d)$. Particularly, the values obtained in steel S275JR are basically coincident with the grain size of this material. In case of steel S355J2 $L$ is 2.38 times $d$. The literature $[11,28,29]$ presents similar results in other steels. Wilshaw [28] found that $L$ and $d$ are equal, whereas for Yokobori [29] the relation gave $L=1.2 d$ for the same material subjected to different heat treatments, and then, presenting different grain sizes.

- The obtained $L$ also explains why no critical radius has been observed in the experimental results: the size of this critical radius has the same order of magnitude as $L$, so the notch radii considered in this paper are well beyond this value.

Additionally, it should be noted that the application of the LM (equation (5)) to the stress-distance curves shown in Figures 10,11 and 12 leads to practically identical results in terms of the critical distance and the inherent strength.

Finally, it is important to notice should be noted that the TCD (and, therefore, the PM and the LM) is based on the linear-elastic fracture mechanics approach. Thus, in principle, this theory may be applied to those situations on which plasticity phenomena are limited, although Susmel and Taylor [19] have demonstrated its suitability in ductile metallic materials. The material conditions analysed in this paper are basically brittle, although in notched conditions there are some plastic phenomena prior to the final cleavage instability. The literature presents a number of significant papers (e.g.,[30-33]) dealing with cleavage fracture which are based on an elastic-plastic approach and on the consideration, explicitly or implicitly, of a material characteristic dimension.

\section{Application of PM and LM for predicting the notch effect on S275JR and S355J2}

The results shown above allow the application of the PM and the LM to be validated for the prediction of the apparent fracture toughness in $\mathrm{S} 275 \mathrm{JR}$, at $-120^{\circ} \mathrm{C}$ and $-90^{\circ} \mathrm{C}$, and in $\mathrm{S} 355 \mathrm{~J} 2$ at $-196^{\circ} \mathrm{C}$, that is, at 
temperatures within the lower shelf of these two materials. To verify this, the predictions provided by equations (7) and (8) will be compared to the experimental values.

Figures 17 to 19 present the different predictions, showing how the PM and the LM provide very similar predictions. It can also be seen that the predictions of the apparent fracture toughness provided by the TCD are generally good. In the case of steel S275JR, these predictions provide accurate safe estimations, given that the predictions basically represent an adjusted lower bound of the experimental results. For higher radius (e.g., $2.0 \mathrm{~mm}$ ) the predictions are less accurate and more conservative. This may be caused by the fact that equations (7) and (8) are derived from linear-elastic considerations and, as seen in figures 7 and 8, the material response becomes more and more non linear when the notch radius increases.

In the case of steel S355J2 the predictions are also good, but on this occasion the deviations at higher radii are non-conservative, with moderate overestimations of the load bearing capacity.

Tables 7 and 8 show the experimental results together with the PM and LM predictions (both the individual result of each test and the experimental mean obtained for each notch radius). It also gathers the corresponding fracture toughness value obtained in cracked conditions. It can be observed that the potential benefits of analysing the fracture process in notched conditions using the TCD, as opposed to not considering the notch effect and assuming crack-like behaviour, are indeed significant.

With all this, the results demonstrate the capacity of the TCD (and both the PM and the LM) for providing predictions of the notch effect in the apparent fracture toughness.

\section{SEM analysis of fracture micromechanisms}

This section gathers the analysis of the fracture micromechanisms performed using Scanning Electron Microscopy (SEM). The authors have previously reported in materials such as PMMA [21] and aluminium alloy Al7075-T651 [22] that, together with the stress relaxation generated by the presence of a given notch, the notch effect also generates an evolution of fracture micromechanisms. Thus, for a given 
material and condition, and assuming brittle behaviour in cracked conditions, the fracture micromechanisms become more and more non-linear when the notch radius increases. Hence, the main aim here is to check whether or not such an evolution in fracture micromechanisms also occurs in the two steels analysed.

Figures 20 to 22 show the fracture micromechanisms observed in specimens with notch radii of $0 \mathrm{~mm}$ (crack-type defect), $0.5 \mathrm{~mm}$ and $2.0 \mathrm{~mm}$. Figure 20 corresponds to steel S275JR at $-120^{\circ} \mathrm{C}$, Figure 21 corresponds to steel S275JR at $-90^{\circ} \mathrm{C}$ and, finally, Figure 22 gathers the observations on steel S355J2 at $196^{\circ} \mathrm{C}$. The specimens included in these figures correspond to those providing intermediate results of $K^{N}{ }_{c}$.

In the first case (Figure 20) it can be observed that the fracture micromechanisms are basically the same whichever the notch radius is. There is a brittle aspect of the fracture surface with cleavages as the fracture micromechanism. Therefore, the introduction of notches of increasing radius is not accompanied by the appearance of ductile mechanisms and the notch effect can only be attributed to the corresponding stress relaxation.

In the second case (Figure 21) it can be observed that the fracture micromechanisms are predominantly brittle for the three radii included in the analysis. However, in the case of specimens with notch radii of $0.5 \mathrm{~mm}$ and $2.0 \mathrm{~mm}$, there are small areas along the initial defect front containing ductile mechanisms (microvoids), these areas being larger for the $2.0 \mathrm{~mm}$ notch radius.

Therefore, the observations are analogous to those made in $[21,22]$ and the notch effect here comprises two different contributions: the stress relaxation at the defect tip, and the evolution in fracture micromechanisms. This may explain the higher notch effect observed at $-90^{\circ} \mathrm{C}$ than that observed at $120^{\circ} \mathrm{C}$

Finally, the third case (Figure 22) shows the fracture micromechanisms in steel S355J2 at $-196^{\circ} \mathrm{C}$. It can be observed that there is no change in fracture micromechanisms, with a brittle aspect of the fracture 
surface and a lack of ductile processes in the three radii being analysed. Therefore the notch effect, which is the lowest one in the three situations here examined, is only caused by the stress relaxation at the defect tip.

The SEM observations also explain the high scatter observed in certain situations, especially concerning $K^{N}{ }_{c}$ in S275JR specimens with a $2.0 \mathrm{~mm}$ notch radius. Figure 23 shows the fracture micromechanisms in two of the steel S275JR specimens. One of them (specimen 2.45) corresponds to the lowest obtained value of $K^{N}$, whereas the other one (specimen 2.48) corresponds to the highest $K_{c}^{N}$. It can be observed how, in the first case, fracture micromechanisms are basically brittle, with little presence of ductile mechanisms, and the notch effect being uniquely caused by the stress relaxation; in the second case there is a significant number of ductile mechanisms (see detail in Figure 24), which generate an additional notch effect to that caused by the stress relaxation. The final effect is much higher $K^{N}$.

\section{Conclusions}

This paper presents the analysis of the notch effect on two materials, steel S275JR and steel S355J2, operating at their corresponding lower shelf and, therefore, following a basically linear-elastic behaviour in cracked conditions. The analysis is based on the experimental results obtained in 72 CT specimens: 24 of them correspond to steel S275JR at $-120^{\circ} \mathrm{C}, 24$ correspond to steel $\mathrm{S} 275 \mathrm{JR}$ at $-90^{\circ} \mathrm{C}$ (the reference temperature, $\mathrm{T}_{0}$, being $-26^{\circ} \mathrm{C}$ ) and the last 24 correspond to steel $\mathrm{S} 355 \mathrm{~J} 2$ at $-196^{\circ} \mathrm{C}$ (with the reference temperature being $-133^{\circ} \mathrm{C}$ ). The experimental results have been measured in terms of the apparent fracture toughness $\mathrm{K}^{\mathrm{N}}$.

A clear notch effect has been observed in the $K^{N}{ }_{c}$ results. This notch effect has been modelled through the Theory of Critical Distances, which has provided reasonably good predictions of the experimental results from which fracture and structural integrity assessments may benefit. The corresponding critical distance of the two materials has the same order of magnitude as the material grain size. 
Finally, the fracture surfaces and micromechanisms have been analysed using Scanning Electron Microscopy. It has been shown how the highest notch effect has occurred in those situations (steel S275JR at $-90^{\circ} \mathrm{C}$ ) where, together with the consubstantial stress relaxation at the defect tip, there has been an evolution of the fracture micromechanisms, with growing non-linear mechanisms when the notch radius increases. Moreover, the fracture micromechanism observations have justified the high experimental scatter observed in S275JR CT specimens with a $2.0 \mathrm{~mm}$ notch radius, given that these specimens providing extreme values correspond to distinct fracture micromechanisms: the highest values are associated with significant development of non-linear processes, whereas the lowest values are associated to basically brittle processes.

\section{Acknowledgements}

The authors of this work would like to express their gratitude to the Spanish Ministry of Science and Innovation for the financial support of the project MAT2010-15721: 'Análisis de integridad estructural en defectos tipo entalla', on the results of which this paper is based.

\section{References}

[1] L.S. Niu, C. Chehimi, G. Pluvinage G, Stress field near a large blunted V notch and application of the concept of notch stress intensity factor to the fracture of very brittle materials Eng. Fract. Mech. 49 (1994) 325-335.

[2] G. Pluvinage, Fatigue and fracture emanating from notch; the use of the notch stress intensity factor, Nucl. Eng. Des. 185 (1998) 173-184.

[3] Y. Bao, Z. Jin, Size effects and mean strength criterion for ceramics, Fatigue Fract. Eng. Mater. Struct. 16 (1993) 829-835.

[4] W. Fenghui, Prediction of intrinsic fracture toughness for brittle materials from the apparent toughness of notched-crack specimen, J. Mater. Sci. 35 (2000), 2543-2546.

[5] M. Creager, C. Paris C, Elastic field equations for blunt cracks with reference to stress corrosion cracking, Int. J. Fract. 3 (1967) 247-252. 
[6] S. Cicero, F. Gutiérrez-Solana, J.A. Álvarez, Structural integrity assessment of components subjected to low constraint conditions, Eng. Fract. Mech. 75 (2008) 3038-3059.

[7] EN 10025-2: Hot rolled products of structural steels- Part 2: Technical delivery conditions for non-alloy structural steels, European Standard, European Committee for Standardization, 2004.

[8] ASTM E1820-11, Standard test method for measurement of fracture toughness, ed. by American Society for Testing and Materials, Philadelphia, 2011.

[9] T.L. Anderson, Fracture mechanics: fundamentals and applications, CRC Press, Florida, 2005.

[10] K. Wallin, The scatter in KIc results, Eng. Fract. Mech. 19 (1984) 1085-1093.

[11] D. Taylor, The theory of critical distances: a new perspective in fracture mechanics, Elsevier, Amsterdam, 2007.

[12] D. Taylor, M. Merlo, R. Pegley, M.P. Cavatorta, The effect of stress concentrations on the fracture strength of polymethylmethacrylate, Mater. Sci. Eng. A382 (2004) 288-294.

[13] H. Neuber, Theory of notch stresses: principles for exact calculation of strength with reference to structural form and material, Springer Verlag, Berlin, 1958.

[14] R.E. Peterson, Metal fatigue, in: G. Sines, J.L. Waisman (Eds.), McGraw Hill, New York, 1959, 293-306.

[15] D. Taylor, G. Wang, The validation of some methods of notch fatigue analysis, Fatigue Fract. Eng. Mater. Struct. 23 (2000) 387-394.

[16] D. Taylor D, A mechanistic approach to critical-distance methods in notch fatigue, Fatigue Fract. Eng. Mater. Struct. 24 (2001) 215-224.

[17] L. Susmel, D. Taylor, Fatigue design in the presence of stress concentrations, J. Strain. Anal. Eng. Des. 38 (2003) 443-452.

[18] D. Taylor, P. Bologna and K. Bel Knani, Prediction of fatigue failure location on a component using a critical distance method, Int. J. Fatigue 22 (2000) 735-742. 
[19] L. Susmel, D. Taylor, On the use of the Theory of Critical Distances to predict failures in ductile metallic materials containing different geometrical features, Eng. Fract. Mech. 75 (2008), $4410-4421$.

[20] L. Susmel, D. Taylor, An elasto-plastic reformulation of the Theory of Critical Distances to estimate lifetime of notched components failing in the low/medium-cycle fatigue regime, J. Eng. Mat. Tech. 132 (2010), 0210021-210028.

[21] S. Cicero, V. Madrazo, I.A. Carrascal, Analysis of notch effect in PMMA by using the Theory of Critical Distances, Eng. Fract. Mech. 86 (2012) 56-72.

[22] V. Madrazo, S. Cicero, I.A. Carrascal, On the point method and the line method notch effect predictions in Al7075-T651, Eng. Fract. Mech. 79 (2012) 363-379.

[23] S. Cicero, V. Madrazo, I.A. Carrascal, On the Point Method load-bearing capacity predictions in Al7075-T651 structural components containing stress risers, Eng. Fail. Anal. 26 (2012) 129-138.

[24] ASTM E112-12, Standard test methods for determining average grain size, ed. by American Society for Testing and Materials, Philadelphia, 2012.

[25] ASTM E1823-12e, Standard terminology relating to fatigue and fracture testing, ed. by American Society for Testing and Materials, Philadelphia, 2012.

[26] ASTM E1921-03, Standard test method for determination of reference temperature, $\mathrm{T}_{0}$, for ferritic steels in the transition range, ed. by American Society for Testing and Materials, Philadelphia, 2003.

[27] ASTM E8/E8M-11, Standard Test Methods for Tension Testing of Metallic Materials, ed. by American Society for Testing and Materials, Philadelphia, 2011.

[28] T.R. Wilshaw, C.A. Rau, A.S. Tetelman, A general model to predict the elastic-plastic stress distribution and fracture strength of notched bars in plane strain bending, Eng. Fract. Mech. 1 (1968) 191-196. 
[29] T. Yokobori, S. Konosu, Effects of ferrite grain size, notch acuity and notch length on brittle fracture stress of notched specimens of low carbon steel, Eng. Fract. Mech. 9 (1977) 839-847.

[30] R.O. Ritchie, J.F. Knott, J.R. Rice, On the relationship between critical tensile stress and fracture toughness in mild steel, J. Mech. Phys. Solids. 21 (1973) 395-410.

[31] D.A. Curry, J.F. Knott, Effects of microstructure on cleavage fracture stress in steel, Metal Science, 11 (1978) 511-514.

[32] T. Lin, A.G. Evans and R.O. Ritchie, A statistical model of brittle fracture by transgranular cleavage, J. Mech. Phys. Solids 34 (1986) 477-497.

[33] J. Watanabe, T. Iwadate, Y. Tanaka, T. Yokoboro, K.Ando, Fracture Toughness in the Transition Region, Eng. Fract. Mech. 28 (1987) 589-600. 
Figure captions.

Figure 1. Schematic showing the different regions of fracture behaviour in ferritic-pearlitic steels

Figure 2. Stress-distance curve at the defect tip, and definition of the PM methodology.

Figure 3. Microstructure of steel S275JR.

Figure 4. Microstructure of steel S355J2.

Figure 5. Schematic showing the geometry of the specimens (dimensions in $\mathrm{mm}$ ). $\rho$ varying from $0 \mathrm{~mm}$ (cracked specimens) up to $2.0 \mathrm{~mm}$.

Figure 6. Experimental setup.

Figure 7. Load-displacement curves obtained in fracture tests performed in specimens with $0,0.5$ and 2.0 $\mathrm{mm}$ notch radius. Steel $\mathrm{S} 275 \mathrm{JR}$ at $-120^{\circ} \mathrm{C}$.

Figure 8. Load-displacement curves obtained in fracture tests performed in specimens with $0,0.5$ and 2.0 $\mathrm{mm}$ notch radius. Steel S275JR at $-90^{\circ} \mathrm{C}$.

Figure 9. Load-displacement curves obtained in fracture tests performed in specimens with $0,0.5$ and 2.0 $\mathrm{mm}$ notch radius. Steel $\mathrm{S} 355 \mathrm{~J} 2$ at $-196^{\circ} \mathrm{C}$

Figure 10. $\mathrm{K}^{\mathrm{N}}{ }_{\mathrm{c}}$ experimental results for $\mathrm{S} 275 \mathrm{JR}$ at $-120^{\circ} \mathrm{C}$. $\rho$ : notch radius.

Figure 11. $\mathrm{K}^{\mathrm{N}}{ }_{\mathrm{c}}$ experimental results for $\mathrm{S} 275 \mathrm{JR}$ at $-90^{\circ} \mathrm{C}$. $\rho$ : notch radius.

Figure 12. $\mathrm{K}^{\mathrm{N}}$ experimental results for $\mathrm{S} 355 \mathrm{~J} 2$ at $-196^{\circ} \mathrm{C}$. $\rho$ : notch radius

Figure 13. Geometry of the model used in FE simulations $(\rho=0.15 \mathrm{~mm})$.

Figure 14. Stress-distance curves considered in the calibration of steel S275JR at $-120^{\circ} \mathrm{C}$.

Figure 15. Stress-distance curves considered in the calibration of steel $\mathrm{S} 275 \mathrm{JR}$ at $-90^{\circ} \mathrm{C}$.

Figure 16. Stress-distance curves considered in the calibration of steel S355J2 at $-196^{\circ} \mathrm{C}$.

Figure 17. Comparison between the experimental data and the predictions provided by the PM (equation (7)) and the LM (equation (8)). S275JR at $-120^{\circ} \mathrm{C}$.

Figure 18. Comparison between the experimental data and the predictions provided by the PM (equation (7)) and the LM (equation (8)). S275JR at $-90^{\circ} \mathrm{C}$.

Figure 19. Comparison between the experimental data and the predictions provided by the PM (equation (7)) and the LM (equation (8)). S355J2 at $-196^{\circ} \mathrm{C}$

Figure 20. Fracture micromechanisms in steel $\mathrm{S} 275 \mathrm{JR}$ at $-120^{\circ} \mathrm{C}$ : a) notch radius $=0 \mathrm{~mm}$, specimen 2.4; b) notch radius $=0.5 \mathrm{~mm}$, specimen 2.13 ; c) notch radius $=2.0 \mathrm{~mm}$, specimen 2.23 . The arrows indicate the initial defect front. 
Figure 21. Fracture micromechanisms in steel $\mathrm{S} 275 \mathrm{JR}$ at $-90^{\circ} \mathrm{C}$ : a) notch radius $=0 \mathrm{~mm}$, specimen 2.28 ; b) notch radius $=0.5 \mathrm{~mm}$, specimen 2.39 ; c) notch radius $=2.0 \mathrm{~mm}$, specimen 2.46 . The arrows indicate the initial defect front.

Figure 22. Fracture micromechanisms in steel $\mathrm{S} 355 \mathrm{~J} 2$ at $-196^{\circ} \mathrm{C}$ : a) notch radius $=0 \mathrm{~mm}$, specimen 3.4 ; b) notch radius $=0.5 \mathrm{~mm}$, specimen $3.15 ; \mathrm{c}$ ) notch radius $=2.0 \mathrm{~mm}$, specimen 3.21 . The arrows indicate the initial defect front.

Figure 23. Fracture micromechanisms in steel S275JR at $-90^{\circ} \mathrm{C}$ : a) notch radius $=2.0 \mathrm{~mm}$, specimen $\left.2.45, \mathrm{~K}^{\mathrm{N}}=226.6 \mathrm{MPam}^{1 / 2} ; \mathrm{b}\right)$ notch radius $=2.0 \mathrm{~mm}$, specimen $2.48, \mathrm{~K}^{\mathrm{N}}{ }_{\mathrm{c}}=830.8 \mathrm{MPam}^{1 / 2}$.

Figure 24.Detail of non-linear mechanisms (microvoids) observed in specimen 2.48 (steel S275JR at $\left.-90^{\circ} \mathrm{C}\right)$ 
Table captions.

Table 1. Chemical composition of the two steels analysed: S275JR and S355J2

Table 2. Fracture toughness results used for the estimation of the reference temperature.

Table 3. Results of the tensile test.

Table 4. Specimen geometry and apparent fracture toughness results in steel S275JR

Table 5. Specimen geometry and apparent fracture toughness results in steel S355J2

Table 6. TDC parameters for the studied materials.

Table 7. Experimental results and predictions of $\mathrm{K}^{\mathrm{N}}{ }_{\mathrm{c}}$ using the TDC (PM and LM) in steel S275JR.

Table 8. Experimental results and predictions of $\mathrm{K}^{\mathrm{N}}{ }_{\mathrm{c}}$ using the TDC (PM and LM) in steel S355J2. 


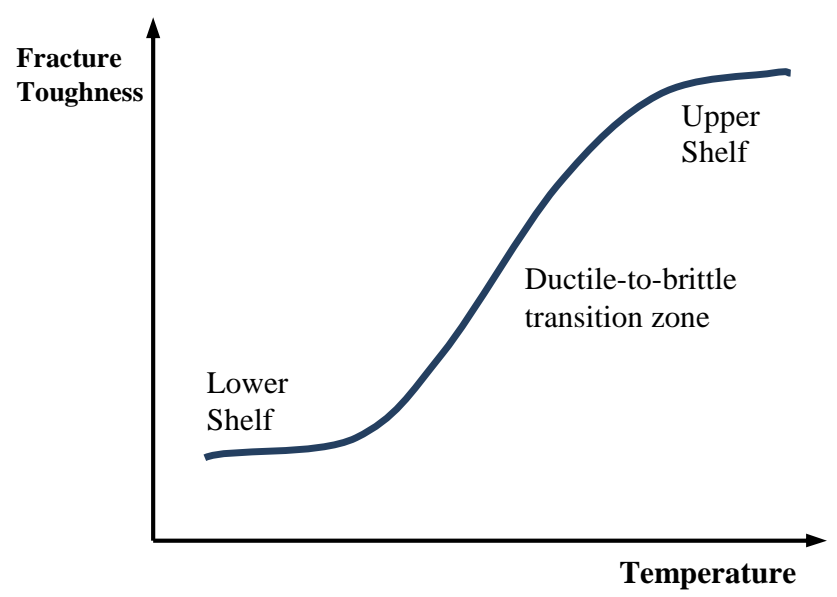

Figure 1. Schematic showing the different regions of fracture behaviour in ferritic-pearlitic steels 


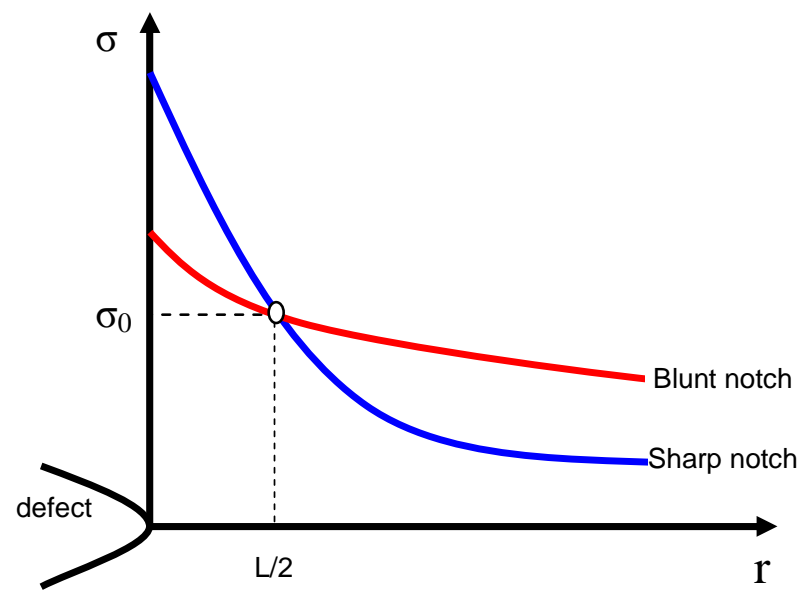

Figure 2. Stress-distance curve at the defect tip, and definition of the PM methodology. 


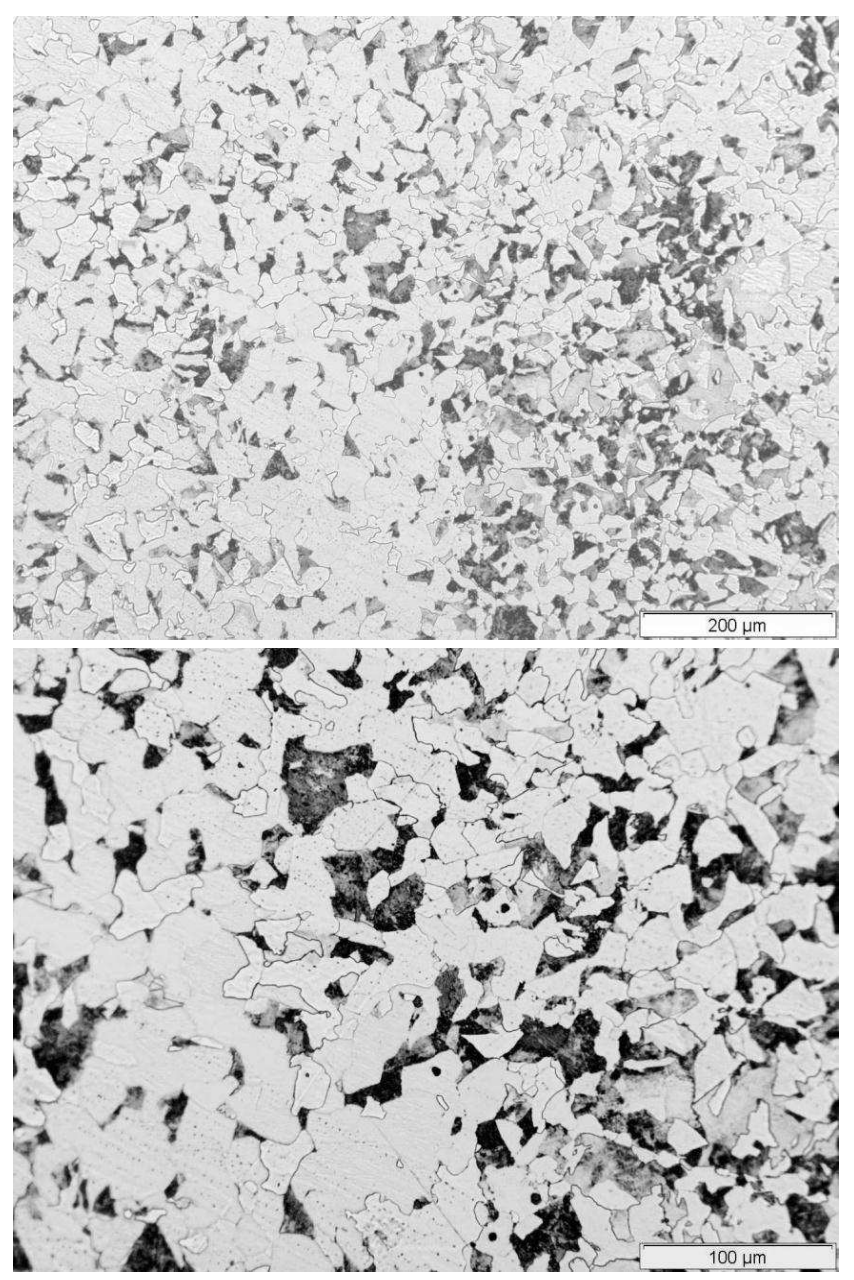

Figure 3. Microstructure of steel S275JR. 


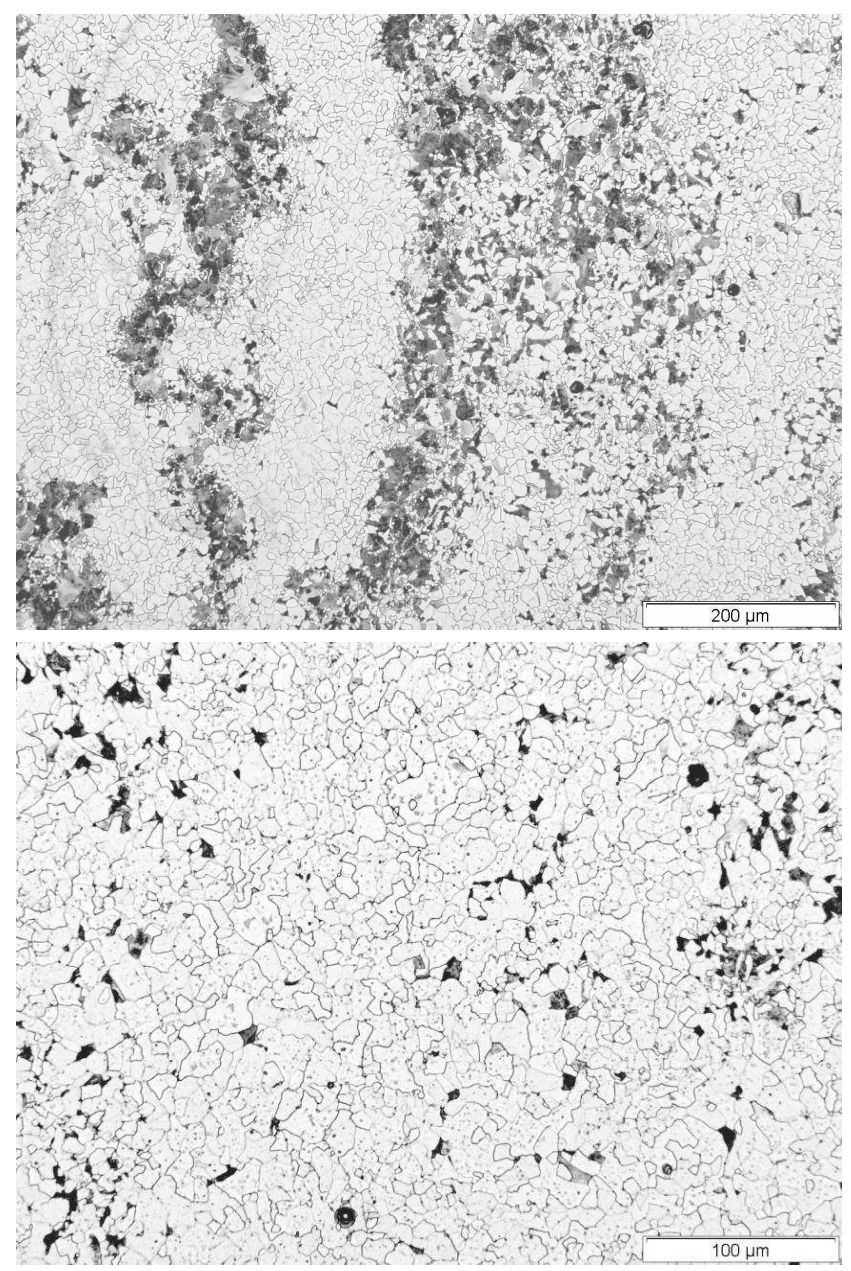

Figure 4. Microstructure of steel S355J2. 


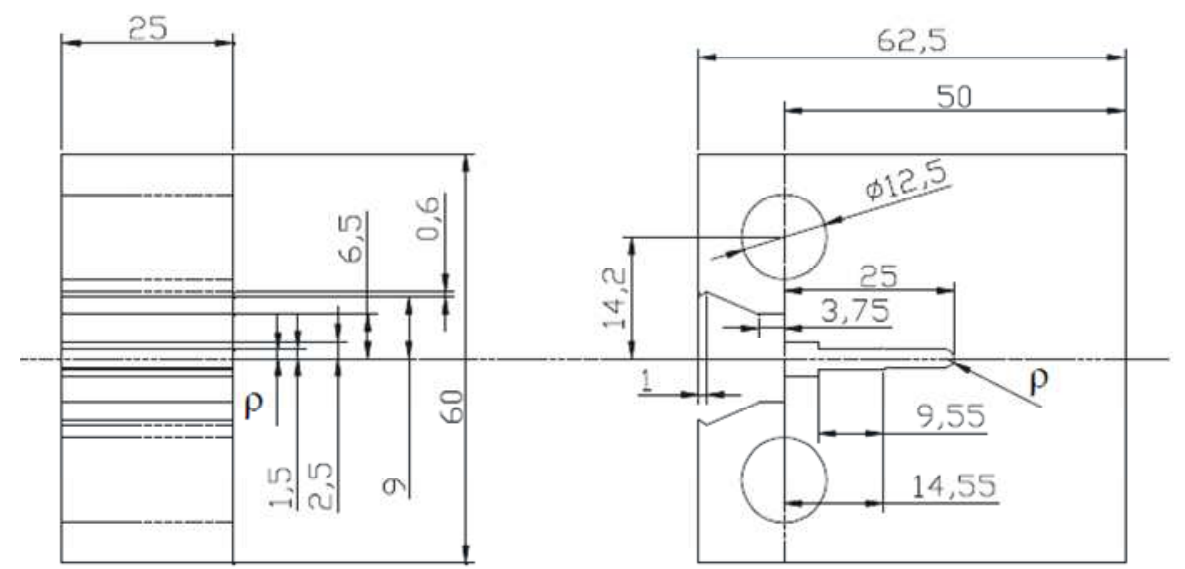

Figure 5. Schematic showing the geometry of the specimens (dimensions in mm). $\rho$ varying from $0 \mathrm{~mm}$ (cracked specimens) up to $2.0 \mathrm{~mm}$. 


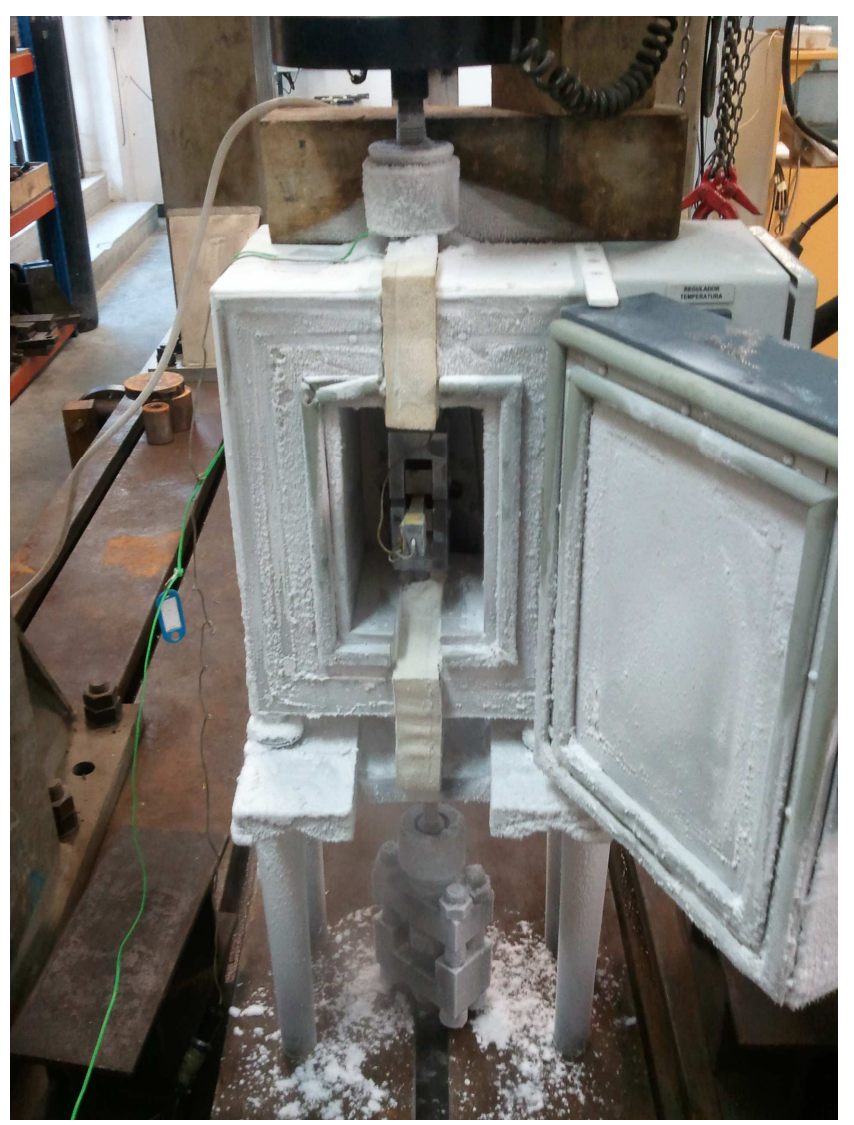

Figure 6. Experimental setup. 


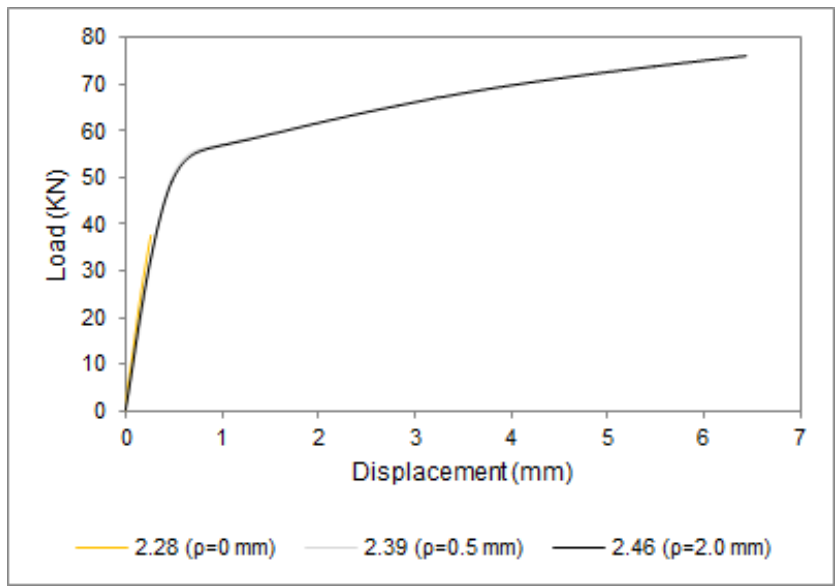

Figure 7. Load-displacement curves obtained in fracture tests performed in specimens with $0,0.5$ and 2.0 $\mathrm{mm}$ notch radius. Steel $\mathrm{S} 275 \mathrm{JR}$ at $-120^{\circ} \mathrm{C}$. 


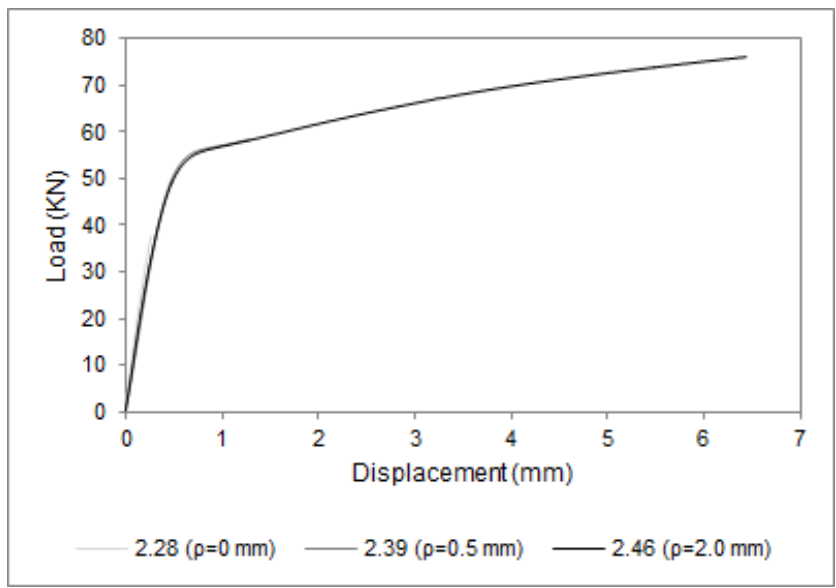

Figure 8. Load-displacement curves obtained in fracture tests performed in specimens with $0,0.5$ and 2.0 $\mathrm{mm}$ notch radius. Steel $\mathrm{S} 275 \mathrm{JR}$ at $-90^{\circ} \mathrm{C}$. 


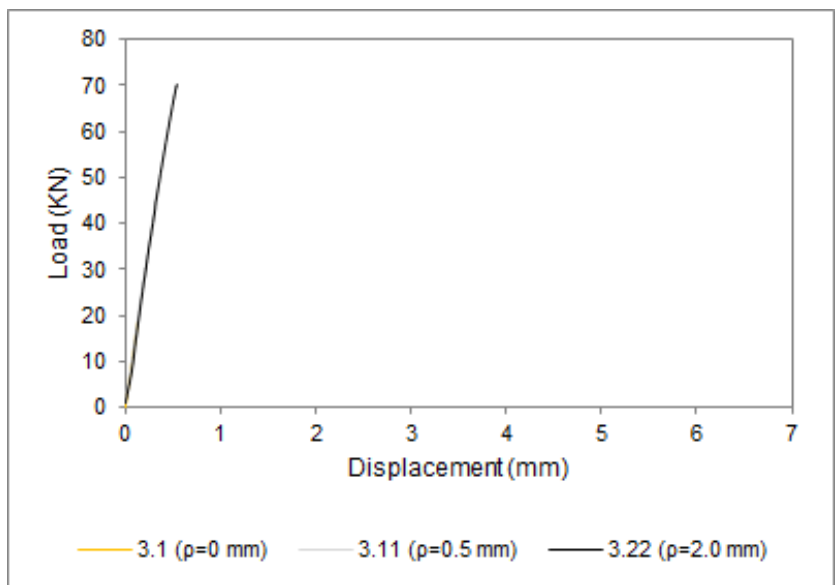

Figure 9. Load-displacement curves obtained in fracture tests performed in specimens with $0,0.5$ and 2.0 $\mathrm{mm}$ notch radius. Steel $\mathrm{S} 355 \mathrm{~J} 2$ at $-196^{\circ} \mathrm{C}$ 


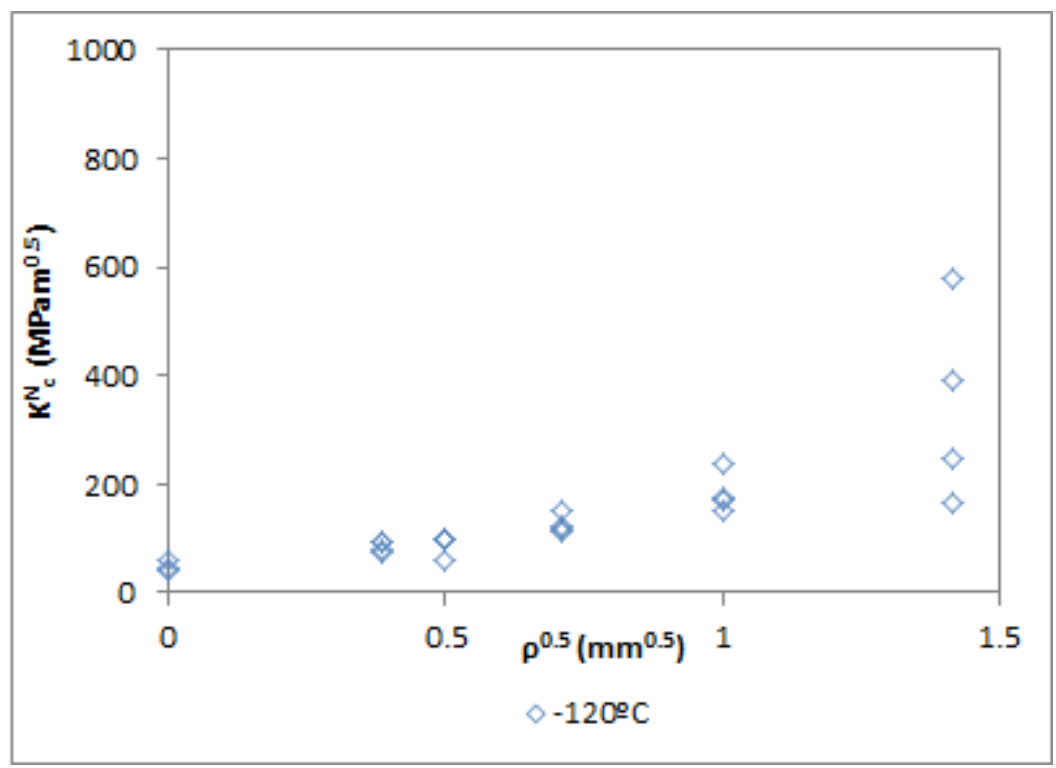

Figure 10. $\mathrm{K}^{\mathrm{N}}{ }_{\mathrm{c}}$ experimental results for $\mathrm{S} 275 \mathrm{JR}$ at $-120^{\circ} \mathrm{C}$. $\rho$ : notch radius. 


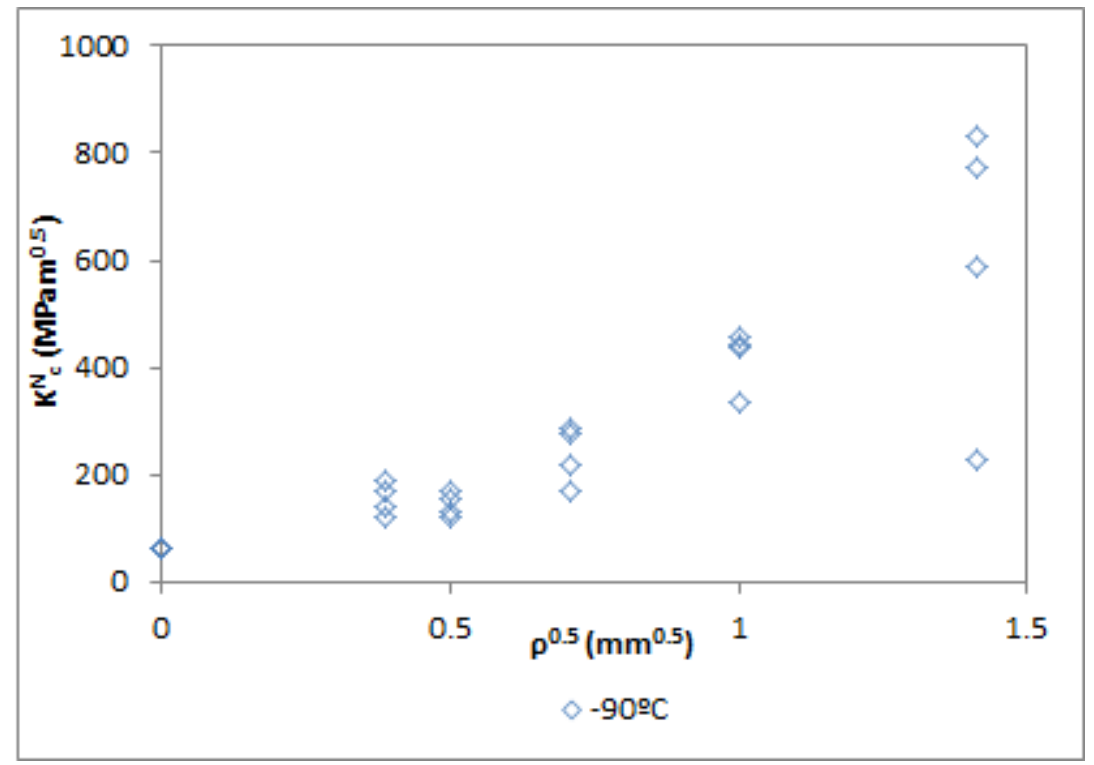

Figure 11. $\mathrm{K}^{\mathrm{N}}{ }_{\mathrm{c}}$ experimental results for S275JR at $-90^{\circ} \mathrm{C}$. $\rho$ : notch radius. 


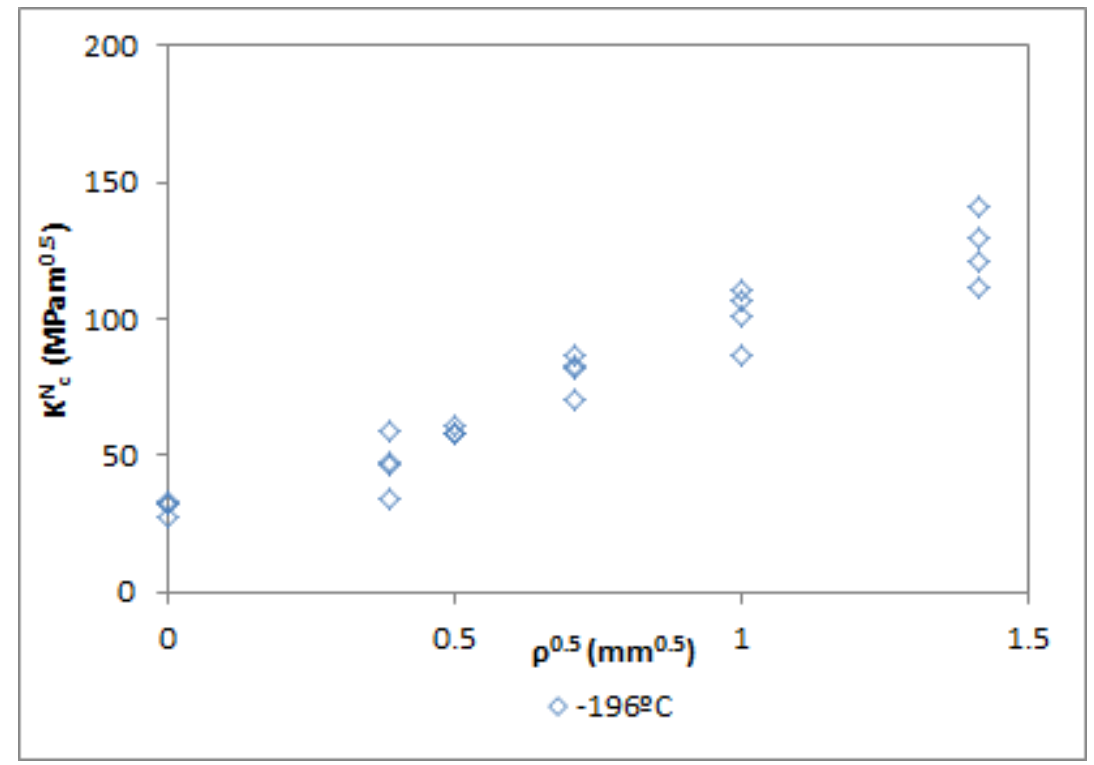

Figure 12. $\mathrm{K}^{\mathrm{N}}{ }_{\mathrm{c}}$ experimental results for $\mathrm{S} 355 \mathrm{~J} 2$ at $-196^{\circ} \mathrm{C}$. $\rho$ : notch radius 


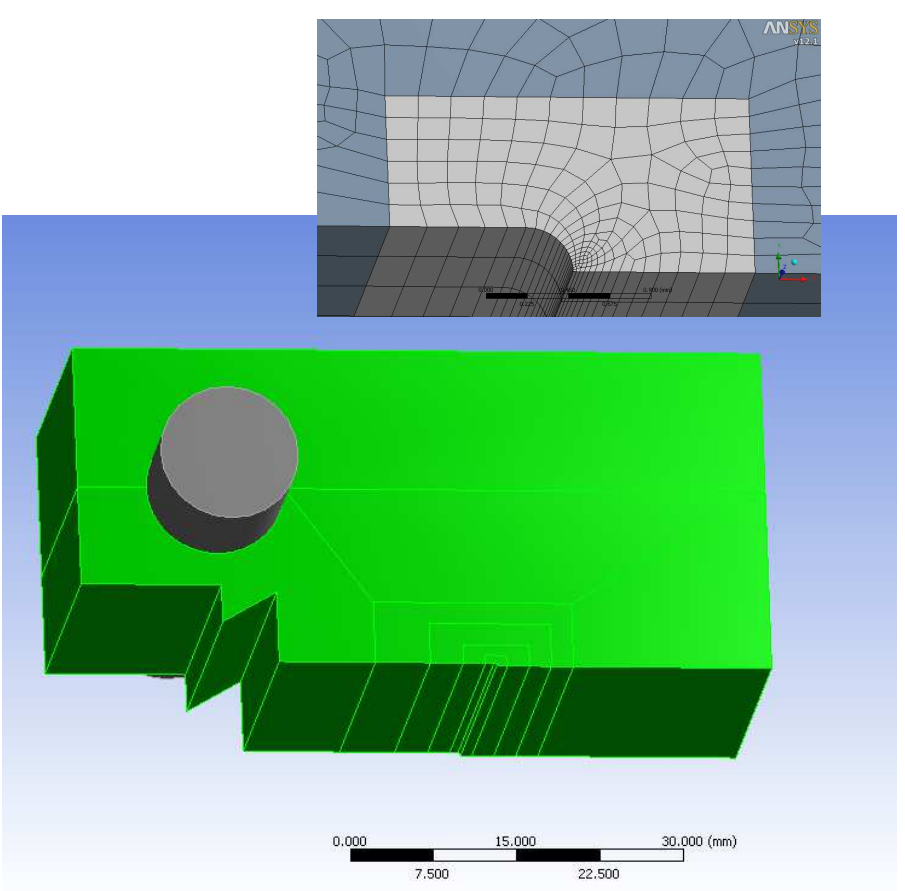

Figure 13. Geometry of the model used in FE simulations $(\rho=0.15 \mathrm{~mm})$. 


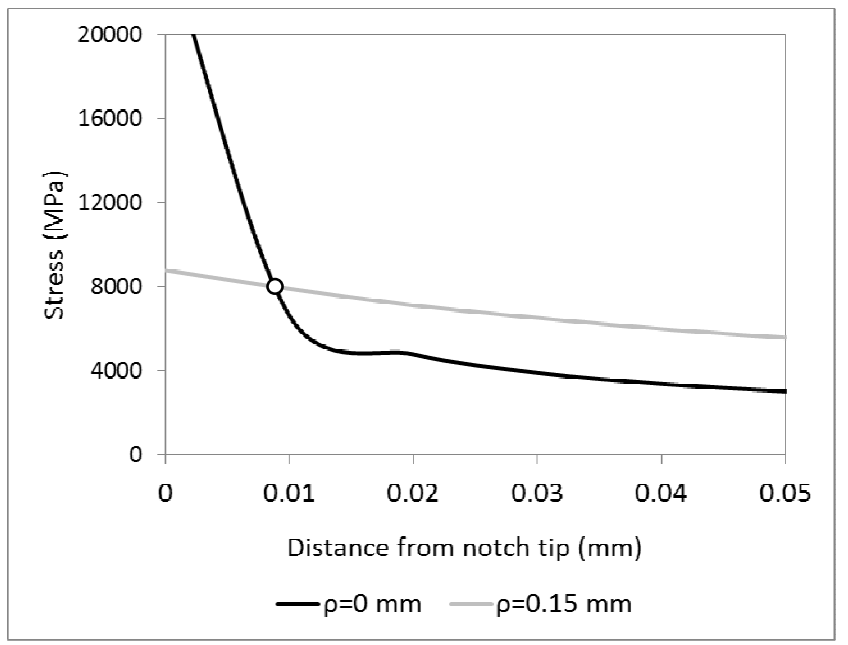

Figure 14. Stress-distance curves considered in the calibration of steel S275JR at $-120^{\circ} \mathrm{C}$. 


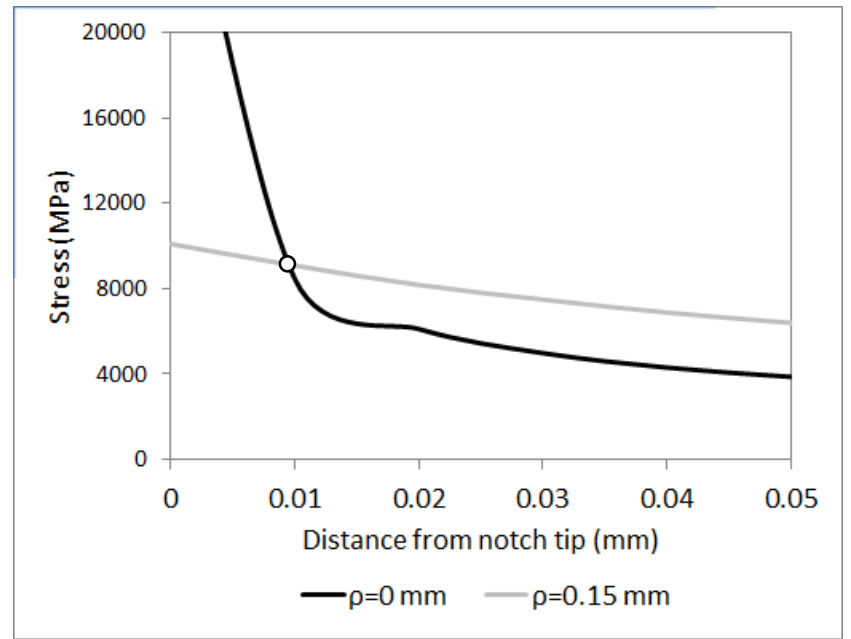

Figure 15. Stress-distance curves considered in the calibration of steel S275JR at $-90^{\circ} \mathrm{C}$. 


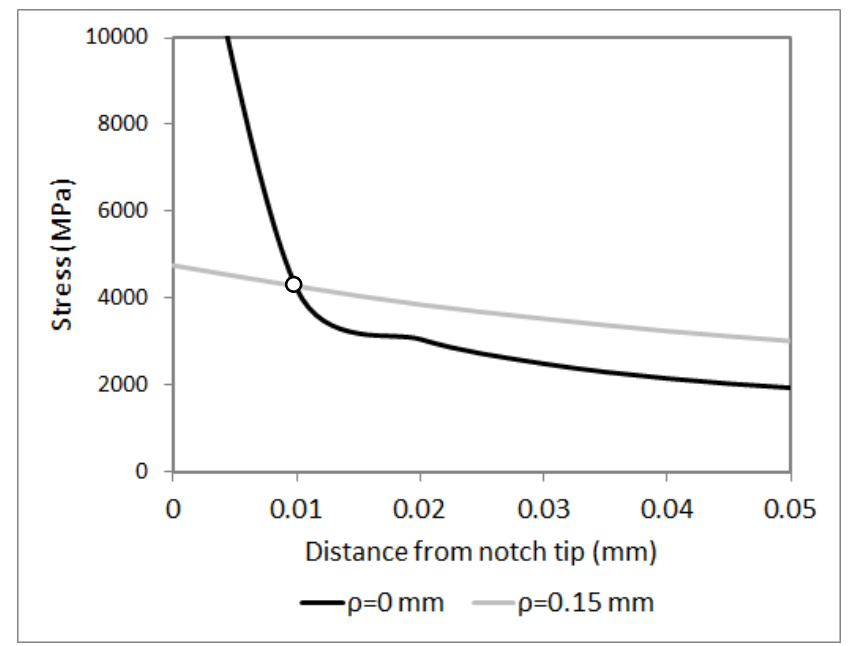

Figure 16. Stress-distance curves considered in the calibration of steel S355J2 at $-196^{\circ} \mathrm{C}$. 


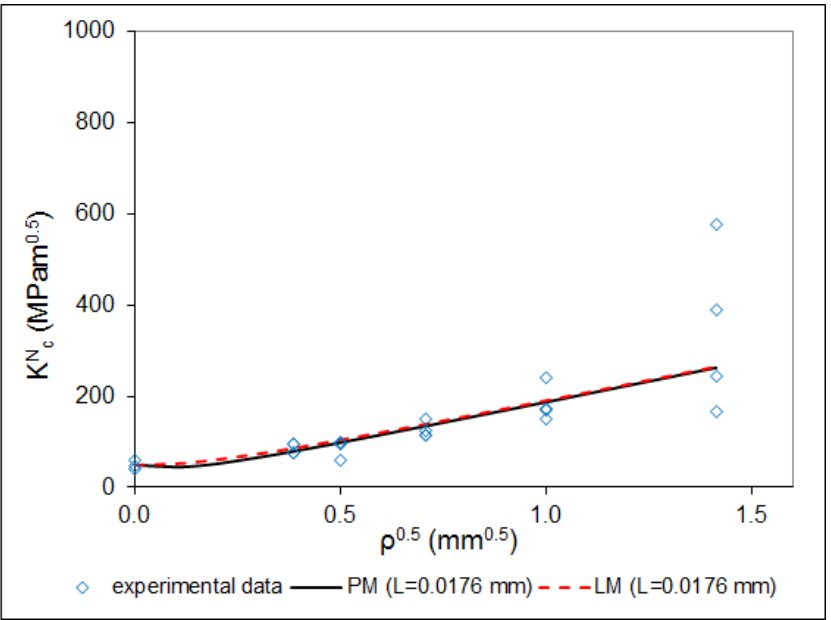

Figure 17. Comparison between the experimental data and the predictions provided by the PM (equation (7)) and the LM (equation (8)). S275JR at $-120^{\circ} \mathrm{C}$. 


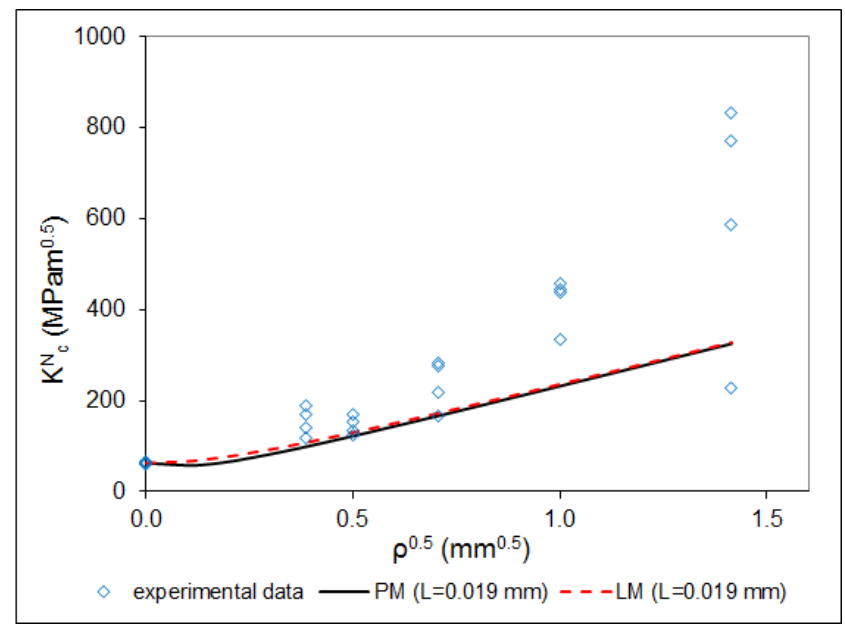

Figure 18. Comparison between the experimental data and the predictions provided by the PM (equation (7)) and the LM (equation (8)). S275JR at $-90^{\circ} \mathrm{C}$. 


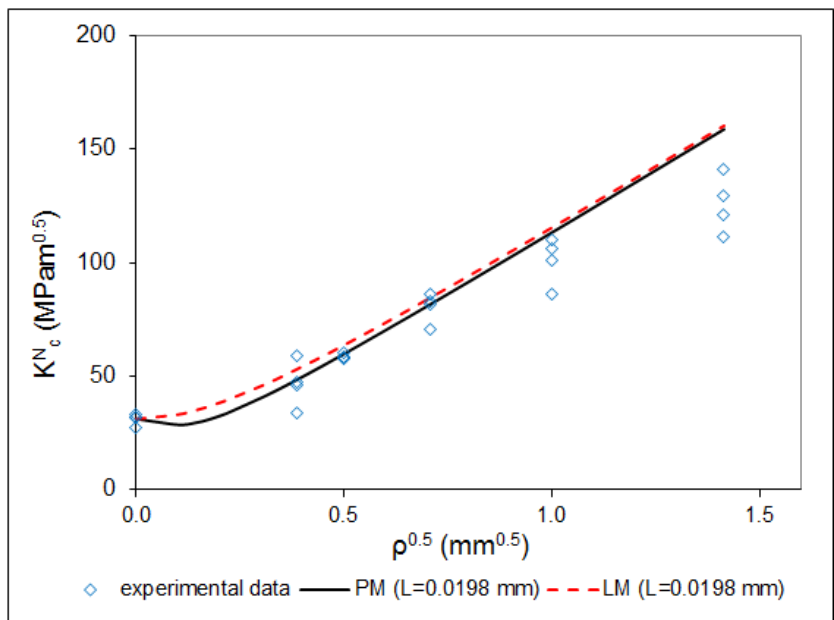

Figure 19. Comparison between the experimental data and the predictions provided by the PM (equation (7)) and the LM (equation (8)). S355J2 at $-196^{\circ} \mathrm{C}$ 

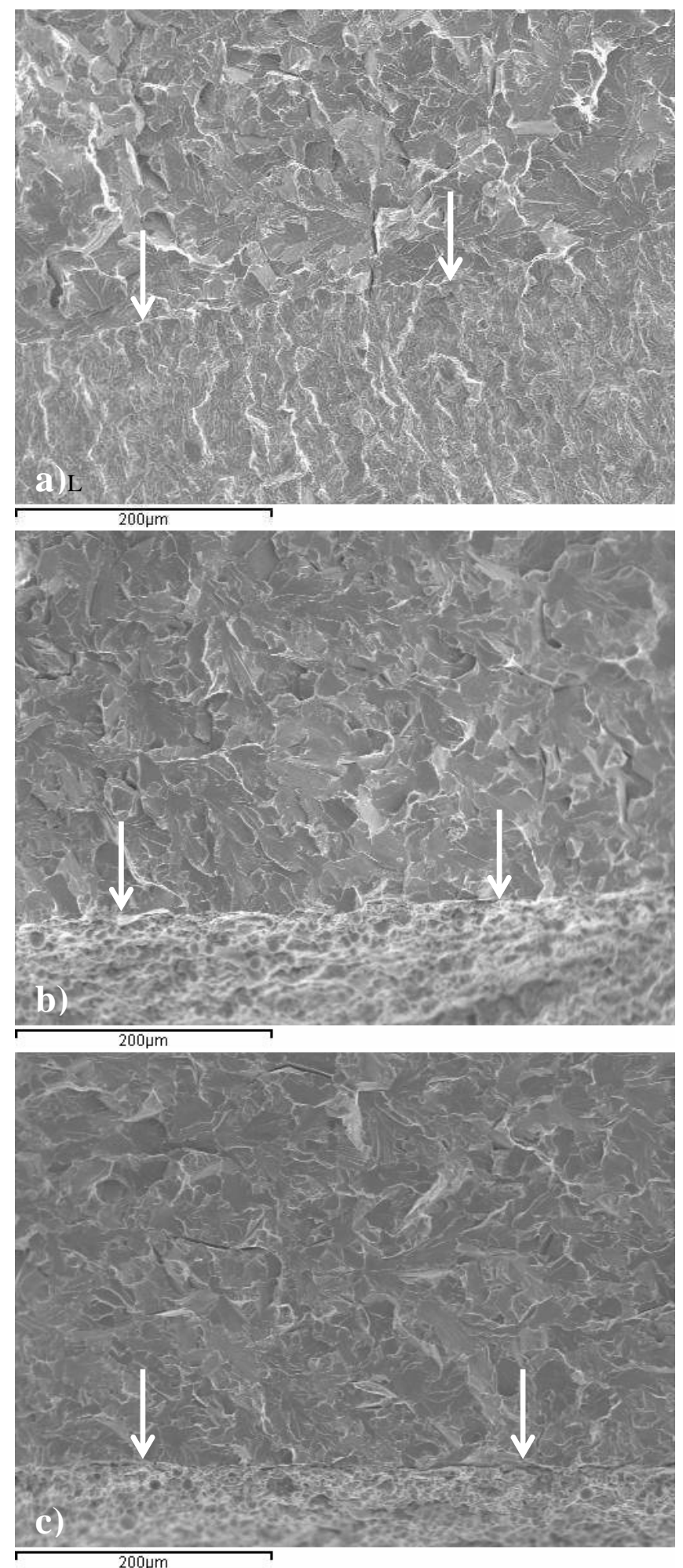

Figure 20. Fracture micromechanisms in steel $\mathrm{S} 275 \mathrm{JR}$ at $-120^{\circ} \mathrm{C}$ : a) notch radius $=0 \mathrm{~mm}$, specimen 2.4; b) notch radius $=0.5 \mathrm{~mm}$, specimen 2.13 ; c) notch radius $=2.0 \mathrm{~mm}$, specimen 2.23 . The arrows indicate the initial defect front. 

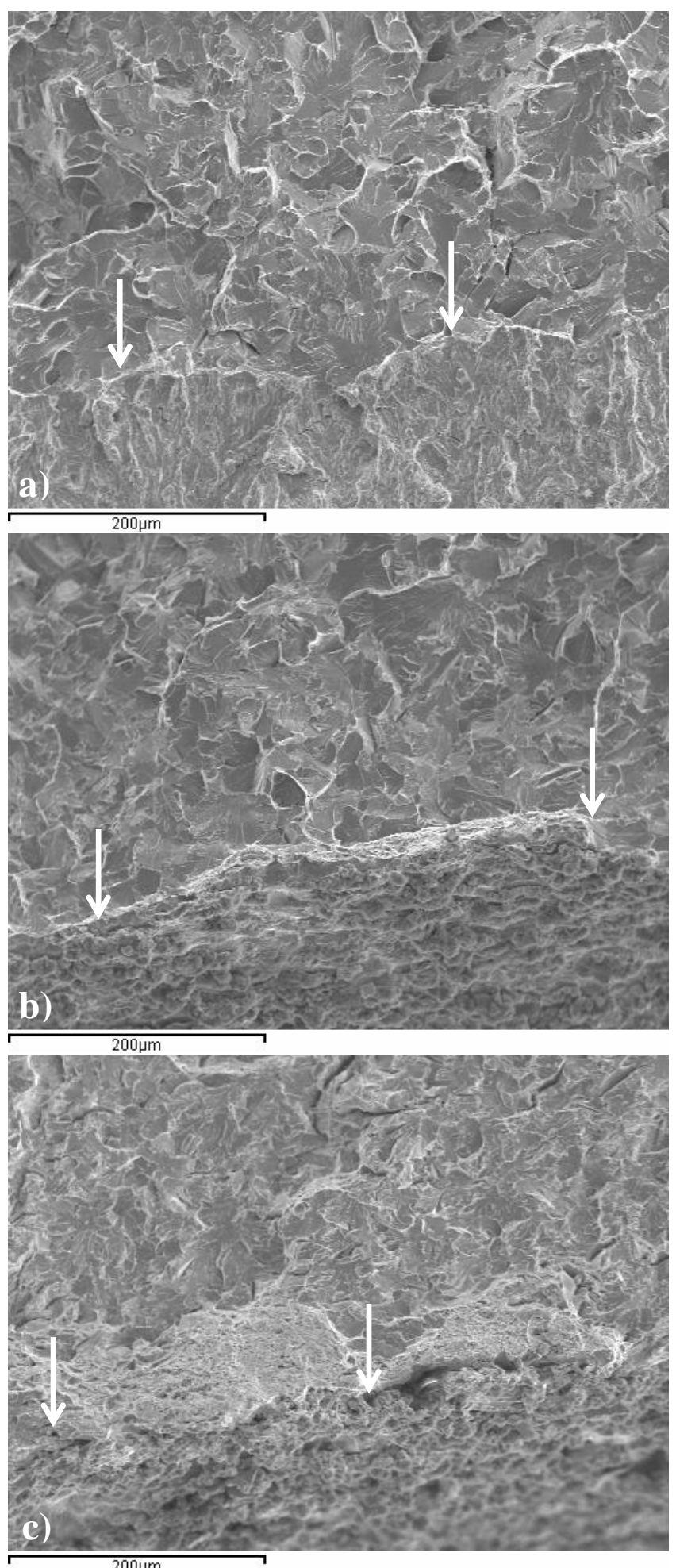

Figure 21. Fracture micromechanisms in steel $\mathrm{S} 275 \mathrm{JR}$ at $-90^{\circ} \mathrm{C}$ : a) notch radius $=0 \mathrm{~mm}$, specimen 2.28 ; b) notch radius $=0.5 \mathrm{~mm}$, specimen 2.39 ; c) notch radius $=2.0 \mathrm{~mm}$, specimen 2.46 . The arrows indicate the initial defect front. 

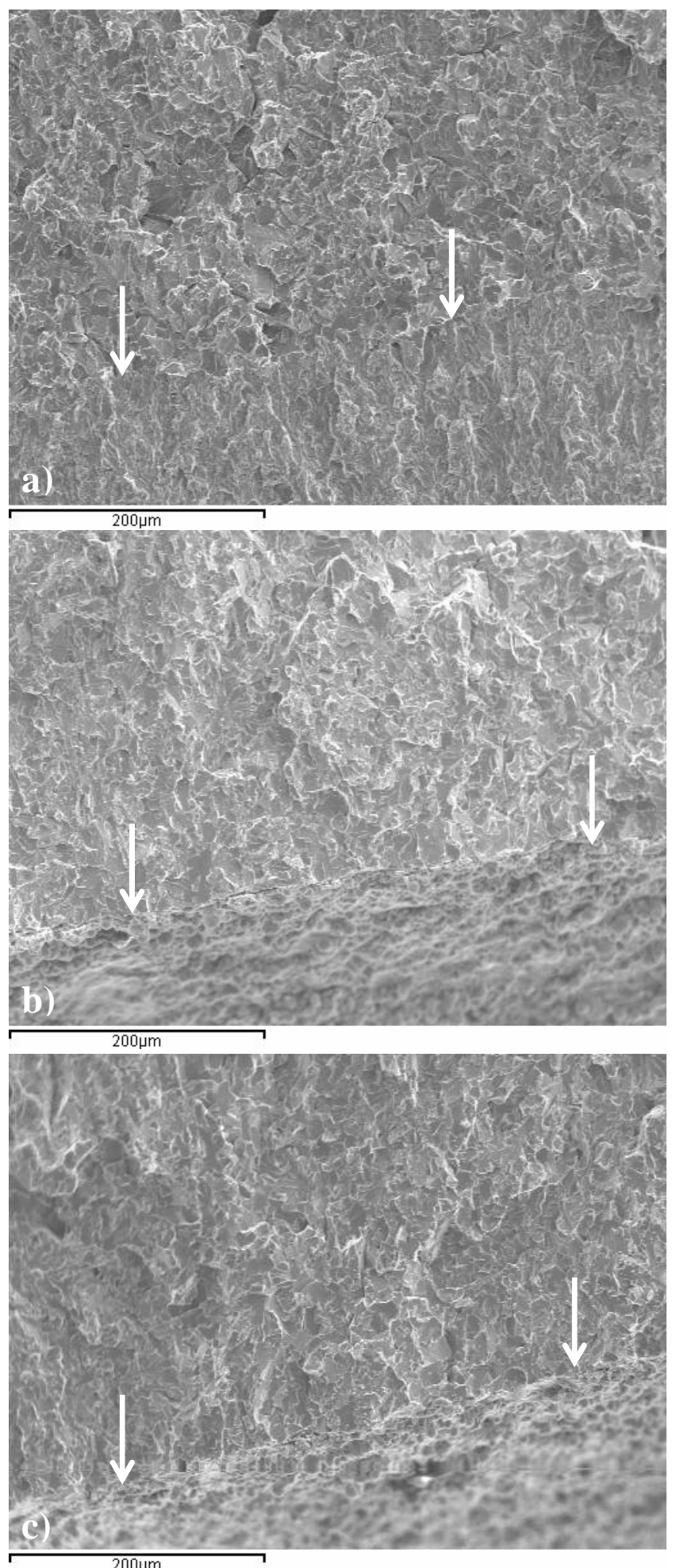

Figure 22. Fracture micromechanisms in steel $\mathrm{S} 355 \mathrm{~J} 2$ at $-196^{\circ} \mathrm{C}$ : a) notch radius $=0 \mathrm{~mm}$, specimen $3.4 ; \mathrm{b}$ ) notch radius $=0.5 \mathrm{~mm}$, specimen $3.15 ; \mathrm{c}$ ) notch radius $=2.0 \mathrm{~mm}$, specimen 3.21 . The arrows indicate the initial defect front. 

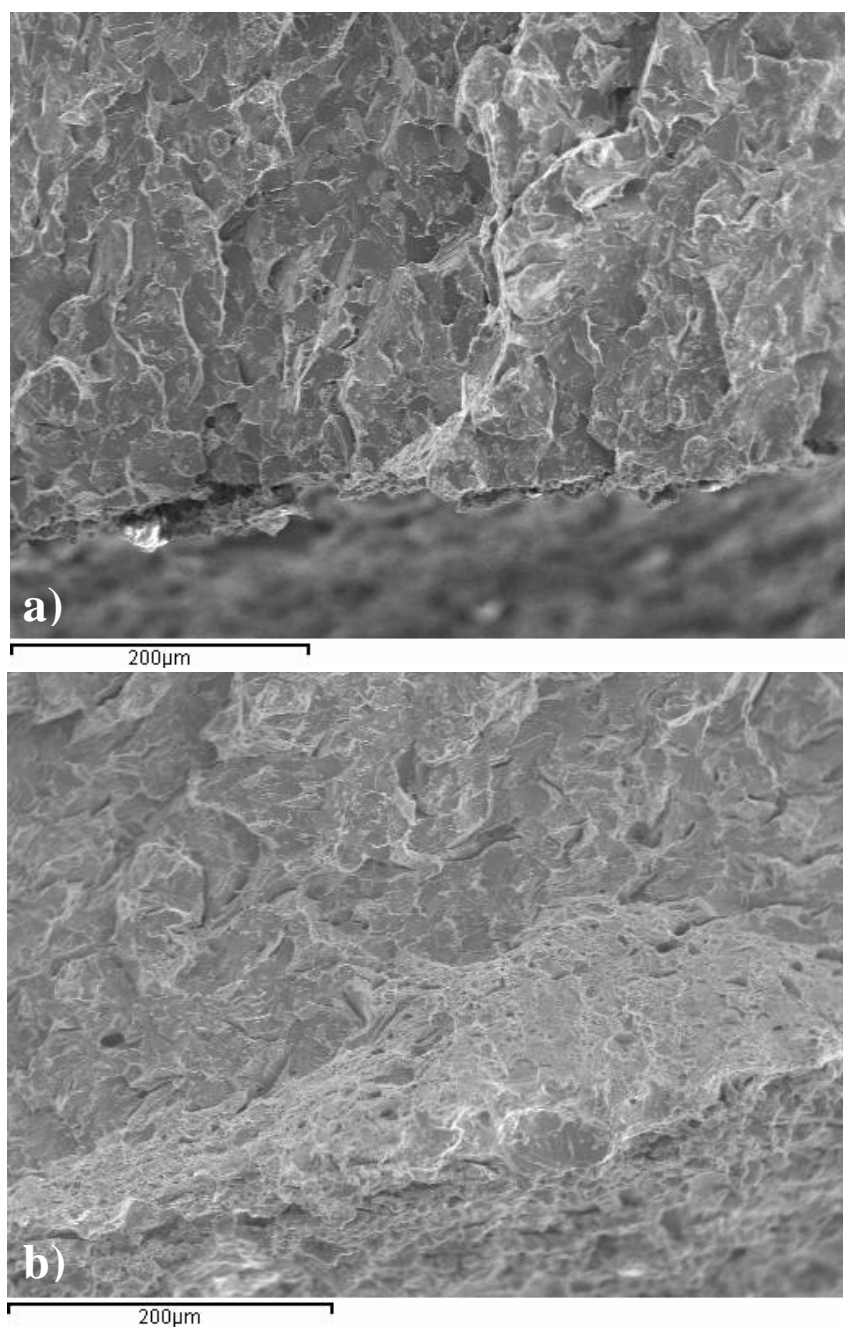

Figure 23. Fracture micromechanisms in steel $\mathrm{S} 275 \mathrm{JR}$ at $-90^{\circ} \mathrm{C}$ : a) notch radius $=2.0 \mathrm{~mm}$, specimen $2.45, \mathrm{~K}^{\mathrm{N}}{ }_{\mathrm{c}}=226.6 \mathrm{MPam}^{1 / 2}$; b) notch radius $=2.0 \mathrm{~mm}$, specimen $2.48, \mathrm{~K}_{\mathrm{c}}^{\mathrm{N}}=830.8 \mathrm{MPam}^{1 / 2}$. 


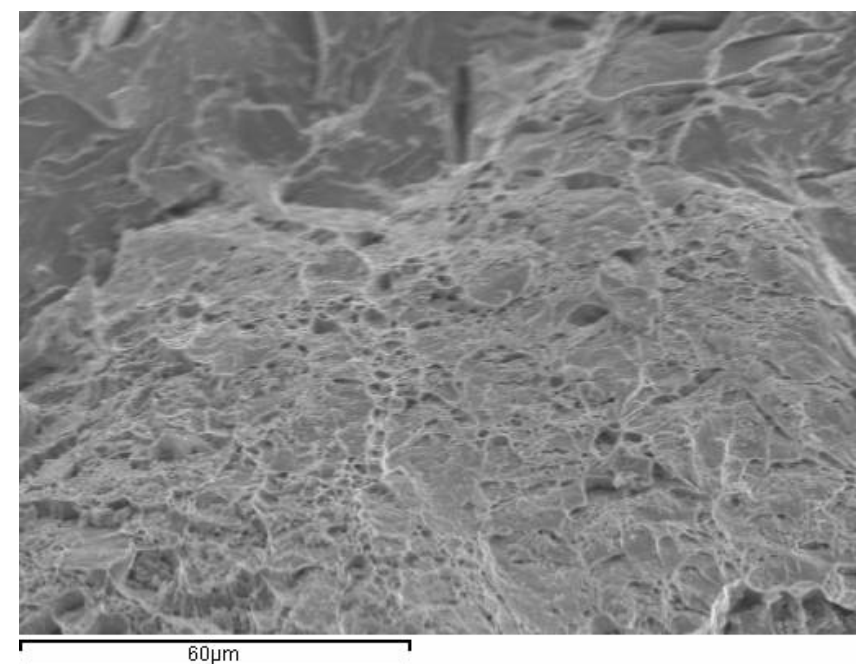

Figure 24.Detail of ductile mechanisms (microvoids) observed in specimen 2.48 (steel S275JR at $-90^{\circ} \mathrm{C}$ ) 
Table 1. Chemical composition of the two steels analysed: S275JR and S355J2 (weight- \%)

\begin{tabular}{|l|c|c|c|c|c|c|c|c|c|c|c|c|}
\hline & $\mathbf{C}$ & $\mathbf{S i}$ & $\mathbf{M n}$ & $\mathbf{P}$ & $\mathbf{S}$ & $\mathbf{~ N i}$ & $\mathbf{C r}$ & $\mathbf{M o}$ & $\mathbf{V}$ & $\mathbf{C u}$ & $\mathbf{T i}$ & $\mathbf{A l}$ \\
\hline $\mathbf{S 2 7 5 J R}$ & 0.18 & 0.26 & 1.18 & 0.012 & 0.009 & $<0.085$ & $<0.018$ & $<0.12$ & $<0.020$ & $<0.06$ & $<0.022$ & 0.034 \\
\hline S355J2 & 0.20 & 0.31 & 1.39 & $<0.012$ & 0.008 & 0.09 & 0.05 & $<0.12$ & 0.02 & $<0.06$ & $<0.022$ & 0.014 \\
\hline
\end{tabular}


Table 2. Fracture toughness results used for the estimation of the reference temperature.

\begin{tabular}{|c|c|c|}
\hline Steel & Test Temperature $\left({ }^{\circ} \mathrm{C}\right)$ & Kc $\left(\right.$ MPam $\left.^{1 / 2}\right)$ \\
\hline \multirow{14}{*}{ S275JR } & \multirow{6}{*}{-10} & 148.5 \\
\hline & & 97.0 \\
\hline & & 105.8 \\
\hline & & 124.2 \\
\hline & & 148.1 \\
\hline & & 113.2 \\
\hline & \multirow{4}{*}{-30} & 80.8 \\
\hline & & 100.1 \\
\hline & & 117.7 \\
\hline & & 104.26 \\
\hline & \multirow{4}{*}{-50} & 61.3 \\
\hline & & 88.0 \\
\hline & & 78.1 \\
\hline & & 95.0 \\
\hline \multirow{14}{*}{ S355J2 } & \multirow{6}{*}{-100} & 136.9 \\
\hline & & 136.1 \\
\hline & & 126.8 \\
\hline & & 216.6 \\
\hline & & 170.5 \\
\hline & & 158.0 \\
\hline & \multirow{4}{*}{-120} & 169.5 \\
\hline & & 153.4 \\
\hline & & 132.6 \\
\hline & & 130.9 \\
\hline & \multirow{4}{*}{-150} & 44.3 \\
\hline & & 63.3 \\
\hline & & 74.1 \\
\hline & & Not valid \\
\hline
\end{tabular}


Table 3. Results of the tensile test. RT: Room Temperature

\begin{tabular}{|c|c|c|c|c|}
\hline & $\begin{array}{c}\mathbf{T} \\
\left({ }^{\circ} \mathbf{C}\right)\end{array}$ & $\begin{array}{c}\mathbf{E} \\
(\mathbf{G P a})\end{array}$ & $\begin{array}{c}\boldsymbol{\sigma}_{\mathbf{y}} \\
(\mathbf{M P a})\end{array}$ & $\begin{array}{c}\mathbf{\sigma}_{\mathbf{u}} \\
(\mathbf{M P a})\end{array}$ \\
\hline \multirow{3}{*}{ S275JR } & $\mathrm{RT}$ & 207 & 328.4 & 518.5 \\
\cline { 2 - 5 } & -120 & 213 & 398.2 & 613.8 \\
\cline { 2 - 5 } & -90 & 211 & 380.5 & 597.3 \\
\hline \multirow{2}{*}{$\mathbf{S 3 5 5 J 2}$} & $\mathrm{RT}$ & 207 & 374.6 & 557.6 \\
\cline { 2 - 5 } & -196 & 218 & 853.5 & 922.9 \\
\hline
\end{tabular}


Table 4. Specimen geometry and apparent fracture toughness results in steel S275JR

\begin{tabular}{|c|c|c|c|}
\hline $\begin{array}{c}\mathrm{T} \\
\left({ }^{\circ} \mathbf{C}\right)\end{array}$ & Specimen & $\underset{(\mathbf{m m})}{\mathbf{\rho}}$ & $\begin{array}{c}\mathbf{K}^{\mathbf{N}}{ }^{1 / 2} \\
\left(\mathbf{M P a m}^{1 / 2}\right)\end{array}$ \\
\hline \multirow{24}{*}{-120} & 2.1 & \multirow{4}{*}{0} & 39.2 \\
\hline & 2.2 & & 60.4 \\
\hline & 2.3 & & - \\
\hline & 2.4 & & 46.8 \\
\hline & 2.5 & \multirow{4}{*}{0.15} & 75.0 \\
\hline & 2.6 & & 77.0 \\
\hline & 2.7 & & 94.8 \\
\hline & 2.8 & & 93.6 \\
\hline & 2.9 & \multirow{4}{*}{0.25} & 97.4 \\
\hline & 2.10 & & 60.3 \\
\hline & 2.11 & & 96.5 \\
\hline & 2.12 & & 97.9 \\
\hline & 2.13 & \multirow{4}{*}{0.5} & 123.6 \\
\hline & 2.14 & & 116.0 \\
\hline & 2.15 & & 113.3 \\
\hline & 2.16 & & 150.6 \\
\hline & 2.17 & \multirow{4}{*}{1} & 239.6 \\
\hline & 2.18 & & 151.4 \\
\hline & 2.19 & & 172.9 \\
\hline & 2.20 & & 169.3 \\
\hline & 2.21 & \multirow{4}{*}{2} & 167.1 \\
\hline & 2.22 & & 578.2 \\
\hline & 2.23 & & 389.6 \\
\hline & 2.24 & & 245.1 \\
\hline \multirow{24}{*}{-90} & 2.25 & \multirow{4}{*}{0} & 64.6 \\
\hline & 2.26 & & 60.5 \\
\hline & 2.27 & & 63.1 \\
\hline & 2.28 & & 62.7 \\
\hline & 2.29 & \multirow{4}{*}{0.15} & 170.3 \\
\hline & 2.30 & & 118.6 \\
\hline & 2.31 & & 190.4 \\
\hline & 2.32 & & 138.9 \\
\hline & 2.33 & \multirow{4}{*}{0.25} & 154.9 \\
\hline & 2.34 & & 122.9 \\
\hline & 2.35 & & 168.7 \\
\hline & 2.36 & & 132.8 \\
\hline & 2.37 & \multirow{4}{*}{0.5} & 167.7 \\
\hline & 2.38 & & 284.2 \\
\hline & 2.39 & & 219.5 \\
\hline & 2.40 & & 274.7 \\
\hline & 2.41 & \multirow{4}{*}{1} & 458.2 \\
\hline & 2.42 & & 333.0 \\
\hline & 2.43 & & 443.2 \\
\hline & 2.44 & & 437.5 \\
\hline & 2.45 & \multirow{4}{*}{2} & 226.6 \\
\hline & 2.46 & & 587.4 \\
\hline & 2.47 & & 771.6 \\
\hline & 2.48 & & 830.8 \\
\hline
\end{tabular}


Table 5. Specimen geometry and apparent fracture toughness results in steel S355J2

\begin{tabular}{|c|c|c|c|}
\hline $\begin{array}{c}\mathbf{T} \\
\left({ }^{\circ} \mathbf{C}\right) \\
\end{array}$ & Specimen & $\begin{array}{c}\mathbf{\rho} \\
(\mathbf{m m})\end{array}$ & $\begin{array}{c}\left.\mathbf{K}^{\mathbf{N}}{ }_{\mathbf{c}}{ }^{1 / 2}\right) \\
\left(\mathbf{P a m}^{1 / 2}\right)\end{array}$ \\
\hline \multirow{24}{*}{-196} & 3.1 & \multirow{4}{*}{ (Im) } & 32.2 \\
\hline & 3.2 & & 27.3 \\
\hline & 3.3 & & 33.5 \\
\hline & 3.4 & & 32.1 \\
\hline & 3.5 & \multirow{4}{*}{0.15} & 46.2 \\
\hline & 3.6 & & 34.1 \\
\hline & 3.7 & & 47.3 \\
\hline & 3.8 & & 59.2 \\
\hline & 3.9 & \multirow{4}{*}{0.25} & 58.4 \\
\hline & 3.10 & & 57.9 \\
\hline & 3.11 & & 60.6 \\
\hline & 3.12 & & 58.1 \\
\hline & 3.13 & \multirow{4}{*}{0.5} & 82.9 \\
\hline & 3.14 & & 86.3 \\
\hline & 3.15 & & 81.6 \\
\hline & 3.16 & & 70.8 \\
\hline & 3.17 & \multirow{4}{*}{1} & 101.4 \\
\hline & 3.18 & & 106.3 \\
\hline & 3.19 & & 86.5 \\
\hline & 3.20 & & 110.5 \\
\hline & 3.21 & \multirow{4}{*}{2} & 129.3 \\
\hline & 3.22 & & 141.1 \\
\hline & 3.23 & & 121.2 \\
\hline & 3.24 & & 111.7 \\
\hline
\end{tabular}


Table 6. TDC parameters for the studied materials.

\begin{tabular}{|c|c|c|c|}
\hline & $\begin{array}{c}\mathbf{T} \\
\left({ }^{\mathbf{O}} \mathbf{C}\right)\end{array}$ & $\begin{array}{c}\mathbf{L} \\
(\mathbf{m m})\end{array}$ & $\begin{array}{c}\mathbf{\sigma}_{\mathbf{0}} \\
(\mathbf{M P a})\end{array}$ \\
\hline \multirow{2}{*}{ S275JR } & -120 & 0.0176 & 8000 \\
\cline { 2 - 4 } & -90 & 0.0190 & 9125 \\
\hline S355J2 & -196 & 0.0198 & 4282 \\
\hline
\end{tabular}


Table 7. Experimental results and predictions of $\mathrm{K}^{\mathrm{N}}{ }_{\mathrm{c}}$ using the TDC (PM and LM) in steel S275JR.

\begin{tabular}{|c|c|c|c|c|}
\hline $\begin{array}{c}\mathrm{T} \\
\left({ }^{\circ} \mathbf{C}\right)\end{array}$ & $\begin{array}{c}\rho \\
(\mathbf{m m})\end{array}$ & $\begin{array}{c}\text { Experimental } \\
\left(\text { MPam }^{1 / 2}\right)\end{array}$ & $\begin{array}{l}\text { PM predict. } \\
\left(\text { MPam }^{1 / 2}\right)\end{array}$ & $\begin{array}{l}\text { LM predict. } \\
\left(\mathrm{MPam}^{1 / 2}\right)\end{array}$ \\
\hline \multirow{23}{*}{-120} & \multirow{3}{*}{0} & 39.2 & \multirow{3}{*}{48.8} & \multirow{3}{*}{48.8} \\
\hline & & 60.4 & & \\
\hline & & - & & \\
\hline & \multirow{4}{*}{0.15} & $\begin{array}{l}40.0 \\
75.0\end{array}$ & \multirow{4}{*}{79.5} & \multirow{4}{*}{86.4} \\
\hline & & 77.1 & & \\
\hline & & 94.9 & & \\
\hline & & 93.6 & & \\
\hline & \multirow{4}{*}{0.25} & 97.4 & \multirow{4}{*}{98.5} & \multirow{4}{*}{104.2} \\
\hline & & 60.3 & & \\
\hline & & 96.5 & & \\
\hline & & 97.9 & & \\
\hline & \multirow{4}{*}{0.5} & 123.7 & \multirow{4}{*}{134.7} & \multirow{4}{*}{139.0} \\
\hline & & 116.1 & & \\
\hline & & 113.4 & & \\
\hline & & 150.7 & & \\
\hline & \multirow{4}{*}{1} & 239.6 & \multirow{4}{*}{187.3} & \multirow{4}{*}{190.4} \\
\hline & & 151.5 & & \\
\hline & & 173.0 & & \\
\hline & & 169.3 & & \\
\hline & \multirow{4}{*}{2} & 167.2 & \multirow{4}{*}{262.6} & \multirow{4}{*}{264.8} \\
\hline & & 578.3 & & \\
\hline & & 389.6 & & \\
\hline & & 245.2 & & \\
\hline & \multirow{4}{*}{0} & 64.6 & \multirow{4}{*}{62.8} & \multirow{4}{*}{62.8} \\
\hline & & 60.6 & & \\
\hline & & 63.2 & & \\
\hline & & 62.7 & & \\
\hline & & 170.3 & & \\
\hline & 015 & 118.7 & 992 & 1082 \\
\hline & 0.13 & 190.4 & & \\
\hline & & 139.0 & & \\
\hline & & 154.9 & & \\
\hline & 025 & 122.9 & 127 & 1300 \\
\hline & 0.25 & 168.7 & 122.4 & 150.0 \\
\hline & & 132.8 & & \\
\hline-90 & & 167.8 & & \\
\hline & 0.5 & 284.2 & 1671 & 1728 \\
\hline & 0.5 & 219.6 & $10 \% .1$ & $1 / 2.8$ \\
\hline & & 274.7 & & \\
\hline & & 458.2 & & \\
\hline & 1 & 333.1 & 2320 & 2362 \\
\hline & 1 & 443.3 & 252.0 & 250.2 \\
\hline & & 437.5 & & \\
\hline & & 226.7 & & \\
\hline & & 587.5 & & 3281 \\
\hline & 2 & 771.6 & 325.1 & 328.1 \\
\hline & & 830.9 & & \\
\hline
\end{tabular}


Table 8. Experimental results and predictions of $\mathrm{K}^{\mathrm{N}}{ }_{\mathrm{c}}$ using the TDC (PM and LM) in steel S355J2.

\begin{tabular}{|c|c|c|c|c|}
\hline $\begin{array}{c}\mathbf{T} \\
\left({ }^{\circ} \mathbf{C}\right)\end{array}$ & $\begin{array}{c}\mathbf{\rho} \\
(\mathbf{m m})\end{array}$ & $\begin{array}{c}\text { Experimental } \\
\left(\text { MPam }^{1 / 2}\right)\end{array}$ & $\begin{array}{c}\text { PM predict. } \\
\left(\text { MPam }^{1 / 2}\right)\end{array}$ & $\begin{array}{c}\text { LM predict. } \\
\left(\text { MPam }^{1 / 2}\right)\end{array}$ \\
\hline \multirow{24}{*}{-196} & \multirow{4}{*}{0} & 32.3 & \multirow{4}{*}{31.3} & \multirow{4}{*}{31.3} \\
\hline & & 27.3 & & \\
\hline & & 33.5 & & \\
\hline & & 32.1 & & \\
\hline & \multirow{4}{*}{0.15} & 46.2 & \multirow{4}{*}{48.7} & \multirow{4}{*}{53.3} \\
\hline & & 34.2 & & \\
\hline & & 47.3 & & \\
\hline & & 59.3 & & \\
\hline & \multirow{4}{*}{0.25} & 58.4 & \multirow{4}{*}{60.0} & \multirow{4}{*}{63.9} \\
\hline & & 58.0 & & \\
\hline & & 60.6 & & \\
\hline & & 58.2 & & \\
\hline & \multirow{4}{*}{0.5} & 82.9 & \multirow{4}{*}{81.8} & \multirow{4}{*}{84.7} \\
\hline & & 86.4 & & \\
\hline & & 81.7 & & \\
\hline & & 70.8 & & \\
\hline & \multirow{4}{*}{1} & 101.4 & \multirow{4}{*}{113.5} & \multirow{4}{*}{115.6} \\
\hline & & 106.3 & & \\
\hline & & 86.6 & & \\
\hline & & 110.5 & & \\
\hline & \multirow{4}{*}{2} & 129.4 & \multirow{4}{*}{158.9} & \multirow{4}{*}{160.5} \\
\hline & & 141.1 & & \\
\hline & & 121.3 & & \\
\hline & & 111.8 & & \\
\hline
\end{tabular}

